\title{
Evaluación de la política pública sobre bioetanol como combustible en Perú, 2003-2019*
}

\author{
Recibido: 7 de octubre de 2019 • Aprobado: 20 de noviembre de 2019 \\ https://doi.org/10.22395//seec.v22n53a6 \\ Yanina Roxana Pacheco Canales**
}

\section{RESUMEN}

La política que el gobierno peruano utiliza para la promoción del bioetanol como combustible no ha logrado los resultados que se esperaban al momento de su diseño. En ese contexto, el objetivo de este artículo es evaluar la política energética. Con esa finalidad, se utilizan los aportes de los expertos en la materia para evaluar la eficacia de los instrumentos empleados y sus impactos. Luego, se analizan los elementos necesarios para replantear el diseño de la política. En consecuencia, se plantea la inclusión del objetivo de disminuir el calentamiento global y la creación de una entidad multisectorial como articuladora del mercado de biocombustibles, además de ajustes que conlleven una política pública con mejores beneficios para la sociedad.

\section{PALABRAS CLAVE}

Política pública; política energética; política industrial; control de emisiones.

\section{CLASIFICACIÓN JEL Q480, L520, Q580}

\section{CONTENIDO}

Introducción; 1. La evaluación de políticas públicas; 2. El bioetanol como biocombustible; 3. Política pública sobre el bioetanol combustible en Perú; 4. Evaluación de la política pública aplicada; 5. Propuesta de cambios en la política pública del bioetanol combustible; Conclusiones y recomendaciones; Referencias.

Este artículo de investigación es resultado del proyecto de investigación Análisis de la política pública sobre el etanol como biocombustible en Perú, financiado con recursos de la autora y ejecutado durante el 2019.

* Economista, Universidad Nacional de Piura (UNP), Piura, Perú. Magíster en Dirección de Empresas, Universidad ESAN, Lima, Perú. Candidata a doctora en Economía, Universidad Nacional Mayor de San Marcos, Lima, Perú. Profesora contratada de la Unidad de Posgrado de la Facultad de Ciencias Económicas, Universidad Nacional Mayor de San Marcos, Lima, Perú. Correo electrónico: yaninaroxanapacheco@gmail.com 


\title{
Evaluation of Public Policy on Bioethanol as a Fuel in Peru
}

\begin{abstract}
The policy that the Peruvian government uses to promote bioethanol as a fuel has not achieved the expected results at the time of its design. In that context, the objective of this article is to evaluate the energy policy. To that end, the contributions of experts in the field are used to assess the effectiveness of the instruments used and their impacts. Then, the necessary elements to rethink the design of the policy are analyzed. Consequently, the inclusion of the objective of reducing global warming and the creation of a multisectoral entity as articulator of the biofuels market are proposed, as well as adjustments that lead to a public policy with better benefits for society.
\end{abstract}

\section{KEYWORDS}

Public policy; energy policy; industrial policy; emission control.

\section{JEL CLASSIFICATION \\ Q480, L520, Q580}

\section{CONTENT}

Introduction; 1. The evaluation of public policies; 2. Bioethanol as a biofuel; 3. Public policy on bioethanol fuel in Peru; 4. Evaluation of the public policy applied; 5 . Proposal of changes in the public policy of bioethanol fuel; Conclusions and recommendations; References.

\section{Avaliação da política pública sobre o bioetanol como combustível no Peru, 2003-2019}

\section{RESUMO}

A política que o governo peruano utiliza para promover o bioetanol como combustível não tem atingido os resultados esperados no momento de seu desenho. Nesse contexto, são utilizadas as contribuições de especialistas na matéria para avaliar a eficácia dos instrumentos empregados e de seus impactos. Logo, são analisados os elementos necessários para repensar no desenho da política. Na consequência, são propostas a inclusão do objetivo de diminuir o aquecimento global e a criação de uma entidade multissetorial como articuladora do mercado de biocombustíveis, além de ajustes que impliquem uma política pública com melhores benefícios para a sociedade.

\section{PALAVRAS-CHAVE}

Política pública; política energética; política industrial; controle de emissões

\section{CLASSIFICAÇÃO JEL}

Q480, L520, Q580

\section{CONTEÚDO}

Introdução; 1. A avaliação de políticas públicas; 2. O bioetanol como biocombustível; 3. Política pública sobre o bioetanol combustível no Peru; 4. Avaliação da política pública aplicada; 5 . Proposta de mudanças na política pública do bioetanol combustível; Conclusões e recomendações; Referências. 


\section{INTRODUCCIÓN}

El agotamiento de los combustibles fósiles, el calentamiento global y la contaminación ambiental son problemas que han despertado preocupación en el mundo, según el Instituto Interamericano de Cooperación para la Agricultura (IICA) (2007). Frente a ello, existe un interés creciente en el desarrollo de fuentes renovables de energía como alternativas a los combustibles fósiles, cuyo consumo tiene un impacto negativo en el ambiente. En este contexto, en varios países se promueve la producción y uso de biocombustibles como una opción energética sostenible.

Perú no es ajeno a la preocupación global, sobre todo porque experimenta una caída sostenida en sus reservas de hidrocarburos, de acuerdo con lo que reporta el Ministerio de Energía y Minas (MEM) (2020). Como parte de la política energética, en Perú se inició la promoción del desarrollo del mercado de los biocombustibles líquidos bioetanol y biodiésel a través de la Ley n. ${ }^{\circ} 28054$. Según el MEM (2007), la ley pretendía, entre otras cosas, (a) desarrollar el sector agropecuario y agroindustrial, reconocidas las condiciones climáticas y agrícolas favorables para tener un costo de producción de bioetanol competitivo; (b) generar empleo en el sector agrícola, en el que miles de peruanos son empleados bajo condiciones inadecuadas; y (c) ofrecer un mercado alternativo a los cultivos con fines ilícitos en algunas zonas del país. Es preciso señalar que el cumplimiento de estos objetivos está condicionado por el abastecimiento del mercado con producción nacional porque requieren de la implementación de proyectos productivos.

En 2019, a 16 años de haberse promulgado la ley, se cuestiona el éxito de la política de promoción de los biocombustibles. Por un lado, los proyectos productivos solo son dos, un número insuficiente para generar un impacto significativo. Por otro lado, estos productores se han visto en la necesidad de exportar sus productos ante el hecho de que el mercado peruano consume principalmente biocombustibles importados, situación que contraviene el espíritu de la ley y en consecuencia, el de la política pública. Por tal motivo, el presente trabajo tiene como finalidad evaluar la política pública peruana utilizada para la promoción de biocombustibles en el caso específico del bioetanol para luego proponer cambios.

El artículo se sustenta en los trabajos de Anderson (2010), Birkland (2011) y Dye (2013), quienes estudian la política pública como un proceso que incluye las etapas de evaluación y diseño. La evaluación de políticas no se limita a la verificación del cumplimiento de los objetivos planteados, sino que se extiende al análisis de todos los impactos de la política en la sociedad. Por su parte, el diseño de políticas tiene cinco elementos que se deben considerar: (a) los objetivos, (b) el modelo causal, (c) las herramientas, (d) los destinatarios y (e) la implementación. En ese sentido, en este 
trabajo se evalúa la política pública y en base a los hallazgos, se proponen mejoras en el diseño de la política a través del análisis de cada uno de sus elementos.

En virtud de lo señalado, el artículo está organizado en seis secciones. La primera parte brinda el marco teórico de la evaluación de políticas públicas. La segunda sección desarrolla conceptos sobre el bioetanol como combustible. En la tercera se describe la política pública sobre el bioetanol combustible aplicada en Perú. La cuarta parte evalúa esta última, para lo cual determina su eficacia. En la quinta sección se plantean propuestas de cambios a la política con base en el análisis de los elementos del diseño. Finalmente, se presentan las conclusiones del trabajo y recomendaciones derivadas de la investigación.

\section{LA EVALUACIÓN DE POLÍTICAS PÚBLICAS}

\subsection{Política pública}

Existen muchas definiciones de política pública en la literatura. Así, para Anderson (2010) es un curso de acción o inacción deliberado y relativamente estable seguido por los actores cuando abordan un problema. Por su parte, Birkland (2011) la define como una declaración del gobierno, a cualquier nivel, de lo que este pretende hacer o no hacer respecto a un problema público. De acuerdo con Dye (2013), las diferentes definiciones examinadas en detalle parecen llegar a lo mismo: una política pública es todo aquello que el gobierno elija hacer o no hacer.

Con base en la versión simplista de Dye, se puede definir política pública como todo aquello que el gobierno, a cualquier nivel, elija hacer o no hacer cuando aborda un problema público.

\subsection{Modelos conceptuales de política pública}

A lo largo de los años se han desarrollado diversos modelos conceptuales para el estudio de las políticas públicas. En ese sentido, Dye (2013) utiliza ocho de estos modelos que, a su juicio, son relevantes: (a) modelo de proceso, (b) modelo institucional, (c) modelo racional, (d) modelo incremental, (e) modelo de grupos, (f) modelo elitista, (g) modelo de elección pública y (h) modelo de teoría de juegos.

Dye (2013) sostiene que ninguno de esos modelos se podría considerar el mejor, sino que cada uno ayuda a entender diferentes aspectos de las políticas públicas. Sin embargo, el modelo de proceso ha demostrado ser útil para organizar el estudio de la política pública. En este sentido, Birkland (2011) y Anderson (2010) estructuran sus obras con el enfoque de la política pública como un proceso. El primer autor señala que el modelo es una forma de aislar y entender los elementos más importantes 
del desarrollo de políticas. El segundo destaca que el enfoque brinda un punto de vista más holístico y real sobre cómo trabaja el gobierno. El gráfico 1 muestra las etapas del proceso de política pública e incluye la posible decisión del gobierno de no hacer nada con respecto al problema.

\section{Gráfico 1. El proceso de la política pública}

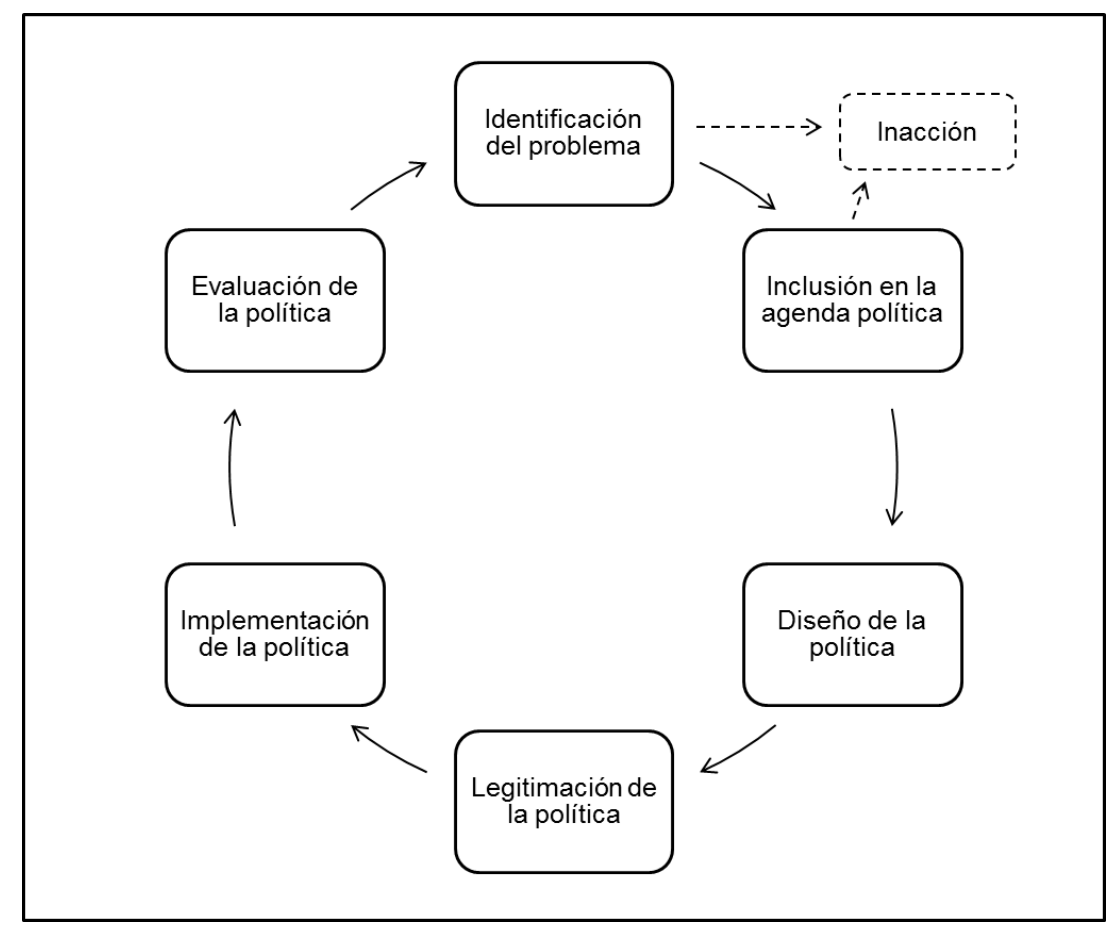

Fuente: elaboración propia con base en Anderson (2010), Birkland (2011) y Dye (2013)

Según este modelo, primero se deben identificar los problemas públicos a través de las demandas de acción gubernamental expresadas por ciudadanos y grupos. Si el problema capta la atención de los formuladores de políticas y deciden discutirlo, entonces se le incluye en la agenda. En este punto se diseñan las políticas, lo que implica el desarrollo de alternativas y la selección de aquellas que se van a utilizar. A continuación, se elaboran leyes u otras disposiciones para cumplir la acción que pretende resolver el problema, es decir que se legaliza o formaliza la política. Para Anderson (2010), la política debe ser, además, legitimada, lo que implica que se le considere justa y apropiada. Luego de ello, se implementan las políticas establecidas, las que posteriormente se evalúan. Sin embargo, también existe la posibilidad de que se decida no hacer nada luego de identificar el problema o incluso, una vez ya agendado. 
Birkland (2011) agrega que los resultados de la evaluación proporcionan retroalimentación al proceso, con lo cual comienza de nuevo y se configura un ciclo. Debido a ello, algunos lo llaman el ciclo de la política, tal como lo precisa Anderson (2010).

El presente trabajo se centra en dos etapas del proceso de políticas públicas: (a) diseño de la política y (b) evaluación de la política.

\subsection{Diseño de políticas públicas}

Smart (2014) y Howlett, Mukherjee y Woo (2015) entienden el diseño de políticas como la etapa en la cual se definen los objetivos y se eligen los instrumentos o herramientas adecuados para cumplir dichos objetivos y así lograr el éxito de las políticas.

El diseño de políticas tiene elementos que se deben considerar de manera explícita. De acuerdo con Birkland (2011), estos elementos son cinco: (a) los objetivos, (b) el modelo causal, (c) las herramientas, (d) los destinatarios y (e) la implementación.

\subsubsection{Los objetivos de la política pública}

Según la Real Academia Española (RAE) (2014), la palabra objetivo u objeto se entiende como el propósito al que se dirige o encamina una acción. Entonces, un objetivo de política pública es el resultado que se busca con una acción gubernamental cuando se aborda un problema público.

Para Birkland (2011), estos objetivos se establecen en la etapa de diseño en función a los problemas identificados. En ese sentido, el autor distingue tres tipos de objetivos de política: (a) eliminar un problema, (b) mantenerse firme ante un problema creciente y (c) reducir un problema a un nivel mejor.

Una vez definidos los objetivos de la política pública, se debe evaluar si existen otras políticas cuyos objetivos entren en conflicto con los primeros. Al respecto, Birkland (2011) resalta la importancia de identificar estos conflictos entre objetivos.

\subsubsection{El modelo causal}

El modelo causal pretende identificar la causa del problema y las alternativas de intervención que lo eliminen, eviten que empeore o que lo mitiguen, según el objetivo planteado. Dunn (2007) utiliza un concepto más amplio: los modelos de políticas como representaciones simplificadas de la realidad, expresadas a manera de conceptos, diagramas, gráficos o ecuaciones matemáticas usadas para describir, explicar y predecir los elementos de una situación problemática. Por su parte, John (2011) plantea que las herramientas de política pública se deben basar en modelos 
causales válidos para tener los efectos esperados.

\subsubsection{Las herramientas de la política pública}

Salamon (2002) define las herramientas o instrumentos de política pública, a las que denomina de acción pública, como métodos identificables a través de los cuales se estructura la acción colectiva para abordar un problema público. Existen muchas clasificaciones de las herramientas de política. Según Salamon (2002), la multidimensionalidad de las herramientas de política ha dificultado que se alcance un consenso sobre su clasificación, incluso en el número de herramientas que existen. Sin embargo, para el autor las diferentes clasificaciones son completamente apropiadas dado que destacan diferentes facetas.

Con el propósito final de evaluar el impacto de las herramientas, John (2011) desarrolla una clasificación dividida en tres grupos, según se puede observar en el gráfico 2.

Gráfico 2. Clasificación de las herramientas de política pública

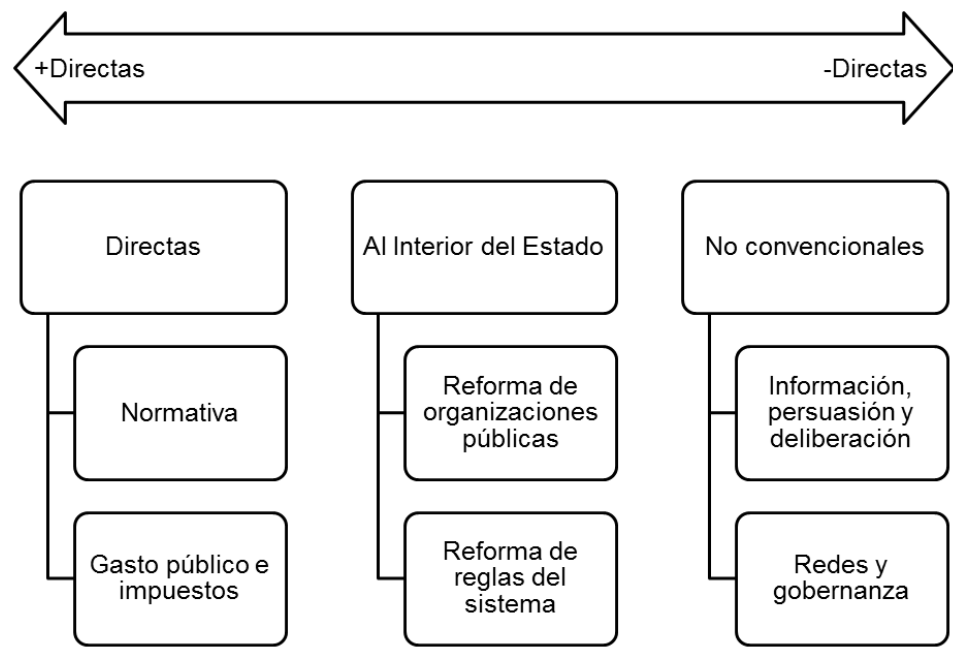

Fuente: elaboración propia con base en John (2011)

\subsubsection{Los destinatarios de la política pública}

Para Birkland (2011), los destinatarios de la política son las entidades, personas u 
organizaciones cuyo comportamiento se busca alterar. Entonces, en la etapa del diseño es necesario identificar no solo a los destinatarios directos, sino también a los indirectos.

\subsubsection{La implementación de la política pública}

A partir de la revisión de los estudios sobre implementación de políticas, Anderson (2010) y Birkland (2011) identifican dos enfoques predominantes. El primer enfoque es el de arriba hacia abajo, en el cual se consideran los objetivos de los formuladores de más alto nivel y a partir de allí, se diseña e implementa la política hasta el nivel más bajo. El segundo considera las habilidades y motivaciones de los implementadores de nivel más bajo y desde ese nivel, se diseña e implementa la política hasta llegar al nivel más alto. Finalmente, la combinación de los dos enfoques anteriores genera un tercero, el enfoque mixto.

Debido a la existencia de estas posibilidades para la implementación, durante la etapa de diseño se debe precisar el enfoque a utilizar.

\subsection{Evaluación de políticas públicas}

Dye (2013) reconoce que algunas definiciones de evaluación de políticas dadas en la literatura la relacionan exclusivamente con el logro de los objetivos planteados, por lo cual -al igual que Anderson (2010)- extiende la noción de evaluación a todos los efectos y consecuencias de la política. Por lo tanto, la evaluación implica saber si las políticas logran los objetivos planteados y en qué medida, además de determinar

Gráfico 3. Clasificación de los impactos de la política pública

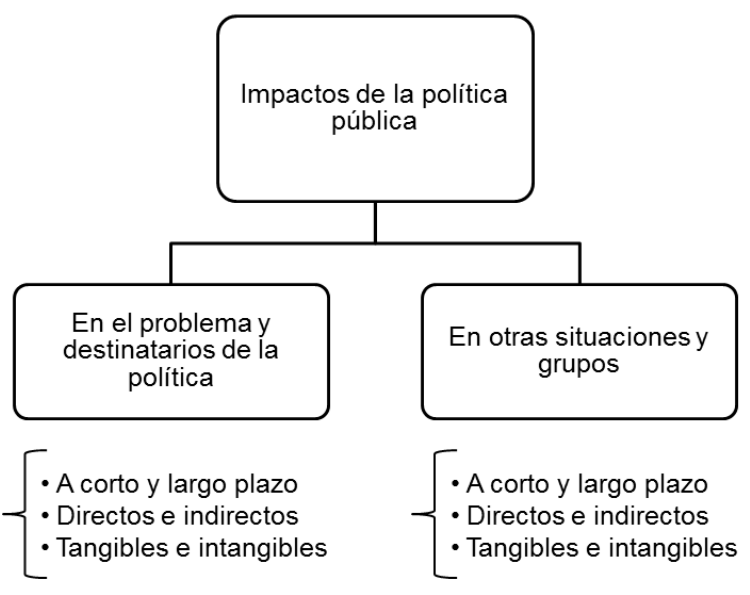


otros efectos en la sociedad, sean intencionados o no.

Ambos autores coinciden en denominar impactos de la política a los efectos y consecuencias que resultan de ella. Los principales impactos se muestran en el gráfico 3.

Por otro lado, Dye (2013) no limita la evaluación de las políticas a las agencias gubernamentales, sino que establece la posibilidad de que la realicen también consultores externos, medios de comunicación y el público en general, como es el caso del presente trabajo.

\section{EL BIOETANOL COMO COMBUSTIBLE}

\subsection{Los biocombustibles}

La Organización de las Naciones Unidas para la Agricultura y la Alimentación (FAO) (2004, p. 39-40) define biocombustible como un "combustible producido directa o indirectamente a partir de la biomasa", entiende a esta última como "materia de origen biológico, excluida la encastrada en yacimientos y formaciones geológicas fosilizadas". La U.S. Energy Information Administration (EIA) (s.f.), además de considerar la naturaleza biológica y no fósil de la biomasa, la considera como fuente renovable de energía. Por consiguiente, los biocombustibles son aquellos combustibles producidos a partir de materia de origen biológico -a excepción de la de origen fósil- que constituyen una fuente de energía renovable.

La FAO (2008) clasifica los biocombustibles según dos criterios. El primer criterio es el origen de la biomasa utilizada para su producción. El segundo es el estado del producto que puede ser sólido, líquido o gaseoso. De esta manera, la clasificación es la presentada en el gráfico 4, en el cual se incluye un ejemplo de cada tipo.

Gráfico 4. Clasificación de los biocombustibles 


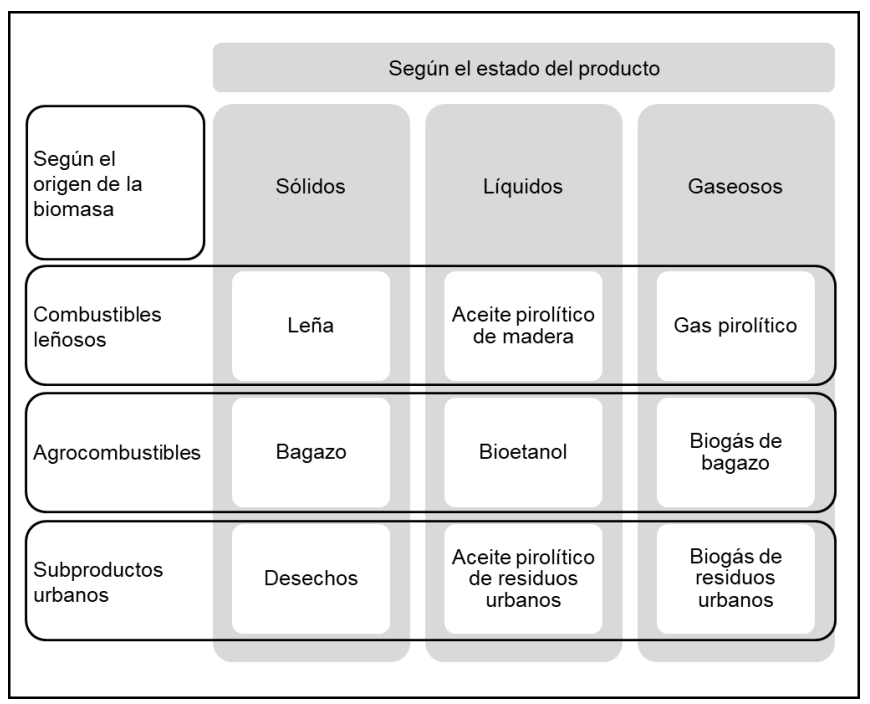

Fuente: elaboración propia con base en FAO (2008)

Pese a la variedad de biocombustibles y de usos que se les da, son los utilizados para el transporte los que han captado la atención en muchos países. El análisis realizado en este documento se centra en los biocombustibles líquidos para actividades de transporte, con el caso específico del bioetanol.

\subsection{El bioetanol}

De acuerdo con Gupta y Demirbas (2010), el etanol, también conocido como alcohol etílico, es un líquido incoloro e inflamable obtenido por dos métodos: (a) el método tradicional que consiste en la fermentación de azúcares, y (b) mediante el proceso químico de hidratación del etileno. Pese a ello, solo el etanol obtenido por el método tradicional se considera un biocombustible porque se produce a partir de biomasa. Algunos autores como Demirbas (2008) utilizan el término bioetanol para referirse a este último, tal como se hace en el presente documento.

El bioetanol utilizado como combustible puede ser hidratado o anhidro, según lo explica Bajpai (2013). El bioetanol hidratado se produce por destilación de azúcares fermentados y contiene agua residual. Se puede ser utilizar directamente como combustible en vehículos diseñados para tal fin, como los llamados flex, producidos en Brasil. Este bioetanol se conoce como alcohol etílico hidratado combustible (AEHC).

El bioetanol anhidro es el resultado de la deshidratación del bioetanol hidratado para poder mezclarlo con gasolinas, lo que da lugar al producto denominado gasohol. A este bioetanol se le conoce como alcohol etílico anhidro combustible (AEAC). En vehículos no diseñados para funcionar con bioetanol, se recomienda utilizar como 
Gráfico 5. Esquematización del proceso productivo del bioetanol combustible

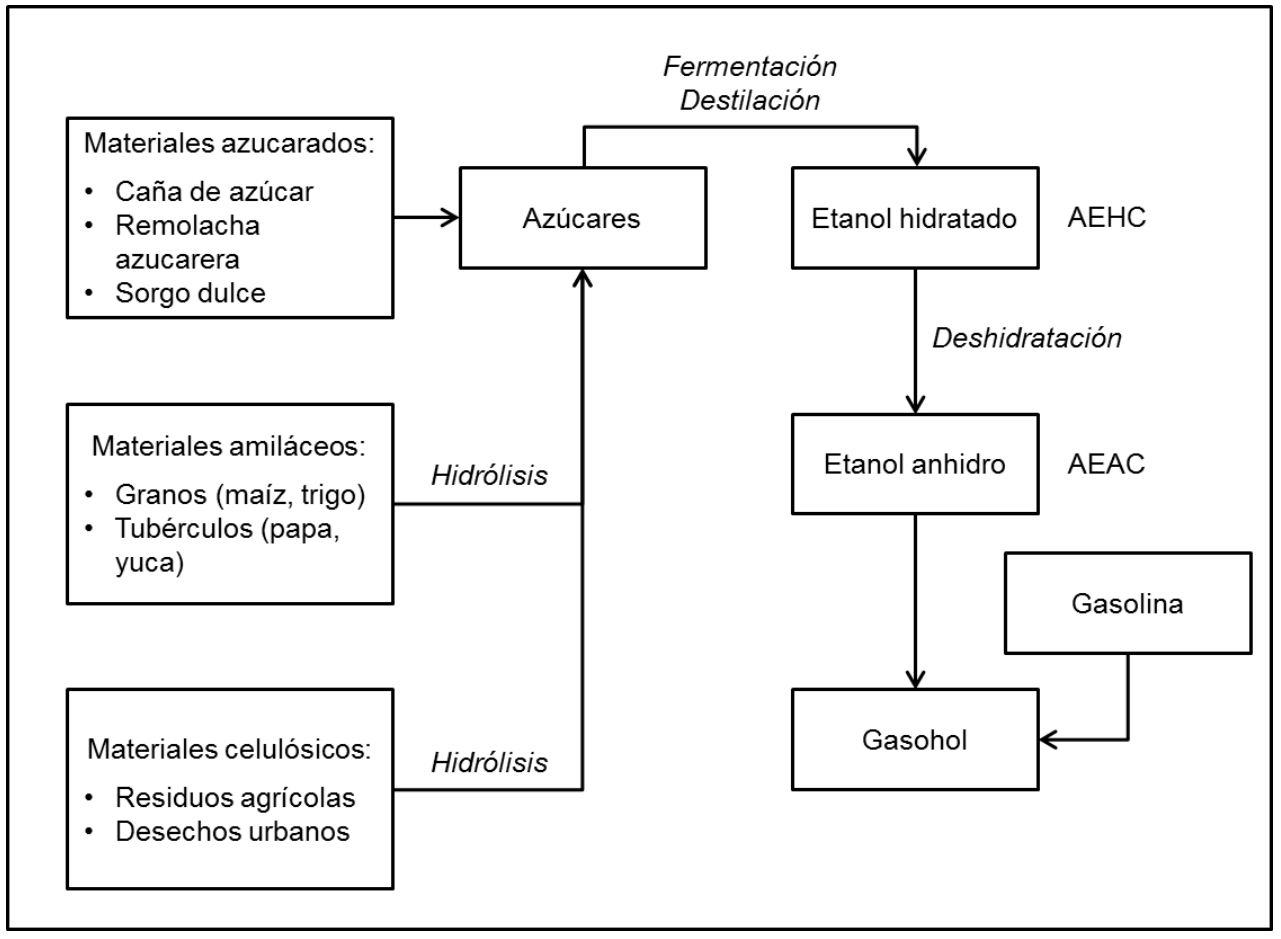

máximo 10 \% de este alcohol en la mezcla, sin necesidad de realizar modificaciones en los vehículos, según sostiene la Comisión Económica para América Latina y el Caribe (Cepal) (2006).

El gráfico 5 muestra un esquema simplificado de la producción del bioetanol, en este se destacan los tres tipos de materias primas y algunos ejemplos relevantes.

Usualmente, los combustibles se someten a un proceso de desnaturalización que consiste en la adición de sustancias nocivas para evitar que se empleen para consumo humano, según lo explican Hill y Kolb (1999).

\section{POLÍTICA PÚBLICA SOBRE EL BIOETANOL COMBUSTIBLE EN PERÚ}

De acuerdo con lo planteado por el IICA (2007), la promoción de la producción y uso de biocombustibles como una opción energética sostenible surgió como respuesta a tres problemas de alcance global: el agotamiento de los combustibles fósiles, el calentamiento global y la contaminación ambiental. 
En ese contexto, después de un estudio preliminar realizado por el Grupo Técnico de Biocombustibles, según el Consejo Nacional del Ambiente (Conam) (2002), se inició la promoción del desarrollo del mercado peruano de biocombustibles con la promulgación de la Ley n. ${ }^{\circ} 28054$. Esta ley constituye el marco general de la política sobre biocombustibles en Perú y se enfoca en el bioetanol anhidro y el biodiésel.

Según el Congreso de la República del Perú (CRP) (2003, p. 1), los objetivos de la Ley n. ${ }^{\circ}$ 28054, denominada Ley de Promoción del Mercado de Biocombustibles, son cinco: "diversificar el mercado de combustibles, fomentar el desarrollo agropecuario y agroindustrial, generar empleo, disminuir la Establece porcentajes obligatorios: 7,8 \% para el ’cer un mercado alternativo en la Lucha contra las $\mathrm{L}$ bioetanol; $2 \%$ y luego $5 \%$ para el biodiésel.

Asimismo, el CRP (2003) establece seis políticas generales en la Ley n. ${ }^{\circ} 28054$, en concordancia con las cuales establece acciones para el cumplimiento de los objetivos. Posteriormente, mediante dos dispositivos legales, el gobierno peruano dispuso medidas adicionales en concordancia con las políticas planteadas en la ley. En el gráfico 6 se pueden ver las acciones implementadas según cada política.

Gráfico 6. Perú: políticas generales y acciones gubernamentales sobre biocombustibles, 2003-2018 
POLITICAS GENERALES

\begin{tabular}{|c|c|c|c|}
\hline $\begin{array}{l}\text { 1. Incentivar la comercialización } \\
\text { de los biocombustibles }\end{array}$ & $\begin{array}{l}\text { Estableceel uso de bioetanol } \\
\text { y biodiesel. } \\
\text { Crea la Comisión Técnica } \\
\text { para proponer (a) porcentajes } \\
\text { de biocombustiblesen } \\
\text { mezclas y cronograma de } \\
\text { aplicación,y (b) programa de } \\
\text { sensibilización respecto a su } \\
\text { uso. }\end{array}$ & $\begin{array}{l}\text { Establece la obligatoriedad de la Norma Técnica } \\
\text { Peruana, garantizada por un certificado de } \\
\text { calidad. } \\
\text { Define los organismos competentes en } \\
\text { producción y comercialización. } \\
\text { Establece porcentajes obligatorios: } 7,8 \% \text { para el } \\
\text { bioetanol; } 2 \% \text { y luego } 5 \% \text { para el biodiésel. } \\
\text { Establece un cronograma de aplicación. Para el } \\
\text { bioetanol fue progresivo hasta el } 01.12 .2011 \text {, } \\
\text { para todos los departamentos, excepto los } \\
\text { amazónicos. }\end{array}$ & 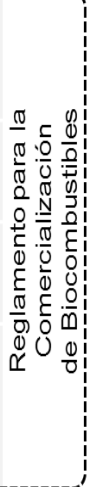 \\
\hline \multirow{2}{*}{$\begin{array}{l}\text { 2. Incentivar la participación } \\
\text { privada }\end{array}$} & $\begin{array}{l}\text { Crea el Programa del Uso de } \\
\text { Biocombustibles (Probiocom). }\end{array}$ & $\begin{array}{l}\text { Ordena emitir las directivas para el } \\
\text { funcionamiento del Probiocom. }\end{array}$ & \\
\hline & & $\begin{array}{l}\text { Somete los proyectos de biocombustibles a la } \\
\text { Ley del Sistema Nacional de Evaluación del } \\
\text { Impacto Ambiental. }\end{array}$ & \\
\hline $\begin{array}{l}\text { 3. Promover la producción de } \\
\text { biocombustibles en la Selva }\end{array}$ & $\begin{array}{l}\text { Designa a la Comisión } \\
\text { Nacional para el Desarrolloy } \\
\text { Vida sin Drogas (Devida) } \\
\text { como promotor de la } \\
\text { inversión privada en cultivos } \\
\text { alternativos. }\end{array}$ & $\begin{array}{l}\text { Le da funcio } \\
\text { la inversión } \\
\text { alternativos. }\end{array}$ & 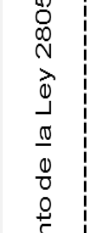 \\
\hline $\begin{array}{l}\text { 4. Desarrollar la estructura } \\
\text { científico-tecnológica para } \\
\text { investigación }\end{array}$ & & \multirow{3}{*}{$\begin{array}{l}\text { Designa al Consejo Nacional de Ciencia, } \\
\text { Tecnología e Innovación Tecnológica (Concytec) } \\
\text { y las universidades como promotores del } \\
\text { desarrollo de nuevas tecnologias en la cadena } \\
\text { de los biocombustibles. }\end{array}$} & $\begin{array}{l}\frac{\pi}{0} \\
0 \\
\mathbb{Q}\end{array}$ \\
\hline $\begin{array}{l}\text { 5. Promover la formación de } \\
\text { recursos humanos de alta } \\
\text { especialización }\end{array}$ & & & \\
\hline $\begin{array}{l}\text { 6. Incentivar la aplicacióny } \\
\text { transferencia de tecnologia }\end{array}$ & & & \\
\hline \multicolumn{2}{|c|}{ Ley 28054} & & \\
\hline
\end{tabular}

Fuente: elaboración propia con base en CRP (2003) y Poder Ejecutivo del Perú (PEP; 2005; 2007; 2008; 2009a; 2010; 2011)

Respecto al bioetanol, las acciones llevadas a cabo por el gobierno peruano constituyen cinco herramientas de política que corresponden a tres tipos, como se plantea en la tabla 1 . 
Tabla 1. Perú: herramientas de política sobre bioetanol combustible, 2003-2018

\begin{tabular}{|c|c|c|}
\hline \multirow{2}{*}{ Políticas generales } & \multicolumn{2}{|c|}{ Herramientas de política } \\
\hline & Tipo & Descripción \\
\hline \multirow{2}{*}{$\begin{array}{l}\text { 1. Incentivar la comercialización de } \\
\text { los biocombustibles. }\end{array}$} & Normativa & $\begin{array}{l}\text { 1. Obligatoriedad del uso del } \\
\text { gasohol (mezcla de gasoli- } \\
\text { na y bioetanol anhidro des- } \\
\text { naturalizado) en la mayoría } \\
\text { de departamentos del país. }\end{array}$ \\
\hline & \multicolumn{2}{|r|}{$\begin{array}{l}\text { 2. Creación de un programa de } \\
\text { sensibilización a los usua- } \\
\text { rios e instituciones públi- } \\
\text { cas con respecto al uso del } \\
\text { bioetanol. }\end{array}$} \\
\hline 2. Incentivar la participación privada. & $\begin{array}{l}\text { Reforma de organizaciones } \\
\text { públicas }\end{array}$ & $\begin{array}{l}\text { 3. Creación del Probiocom } \\
\text { para promover las inversio- } \\
\text { nes en biocombustibles. }\end{array}$ \\
\hline $\begin{array}{l}\text { 3. Promover la producción de biocom- } \\
\text { bustibles en la selva. }\end{array}$ & $\begin{array}{l}\text { Reforma de organizaciones } \\
\text { públicas }\end{array}$ & $\begin{array}{l}\text { 4. Dotación de funciones a la } \\
\text { Devida como promotora de } \\
\text { la inversión privada en cul- } \\
\text { tivos alternativos. }\end{array}$ \\
\hline $\begin{array}{l}\text { 4. Desarrollar la estructura científico- } \\
\text { tecnológica para investigación. }\end{array}$ & \multirow{3}{*}{$\begin{array}{l}\text { Reforma de organizaciones } \\
\text { públicas }\end{array}$} & \multirow{3}{*}{$\begin{array}{l}\text { 5. Designación del Concytec } \\
\text { y las universidades como } \\
\text { promotores del desarrollo } \\
\text { de nuevas tecnologías en la } \\
\text { cadena de los biocombusti- } \\
\text { bles. }\end{array}$} \\
\hline $\begin{array}{l}\text { 5. Promover la formación de recur- } \\
\text { sos humanos de alta especialización. }\end{array}$ & & \\
\hline $\begin{array}{l}\text { 6. Incentivar la aplicación y transfe- } \\
\text { rencia de tecnología. }\end{array}$ & & \\
\hline
\end{tabular}

Fuente: elaboración propia con base en CRP (2003) y PEP (2005; 2007; 2008; 2009a; 2010; 2011)

\section{EVALUACIÓN DE LA POLÍTICA PÚBLICA APLICADA}

La política pública sobre el bioetanol en Perú se evalúa en dos partes. La primera parte corresponde al análisis de los impactos en el problema y en los destinatarios de la política, se realiza mediante la verificación del cumplimiento de los objetivos de esta última, además de analizar otros impactos en los destinatarios de la política. La segunda parte es la evaluación de los impactos en otras situaciones y grupos, es decir, los efectos colaterales derivados de la aplicación de la política.

\subsection{Impactos en el problema y destinatarios de la política}

Primero se debe verificar el cumplimiento de los objetivos de la política, para lo cual es necesario entenderlos. Como se mencionó anteriormente, la promoción del 
mercado de biocombustibles en Perú tiene cinco objetivos, como se presenta en el gráfico 7. No obstante, únicamente los objetivos 1, 2 y 4 son independientes. Así, promover el mercado de biocombustibles en primera instancia busca diversificar el mercado de combustibles, fomentar el desarrollo agropecuario y agroindustrial, y disminuir la contaminación ambiental.

Por otro lado, los objetivos 3 y 5 de generar empleo y ofrecer un mercado alternativo en la lucha contra las drogas, están ligados al número 2 de fomentar el desarrollo agropecuario y agroindustrial. La relación de estos objetivos se evidencia en el marco conceptual que justifica el Reglamento para la Comercialización de Biocombustibles, expuesto por el MEM (2007). De acuerdo con lo planteado por esta institución, el cultivo de materias primas y su posterior transformación en biocombustibles constituyen fuentes de empleo, además de ser una alternativa al cultivo de coca con fines ilícitos. Por lo expuesto, estos tres objetivos se analizan de forma conjunta.

Gráfico 7. Perú: relación entre los objetivos planteados en la política del bioetanol combustible

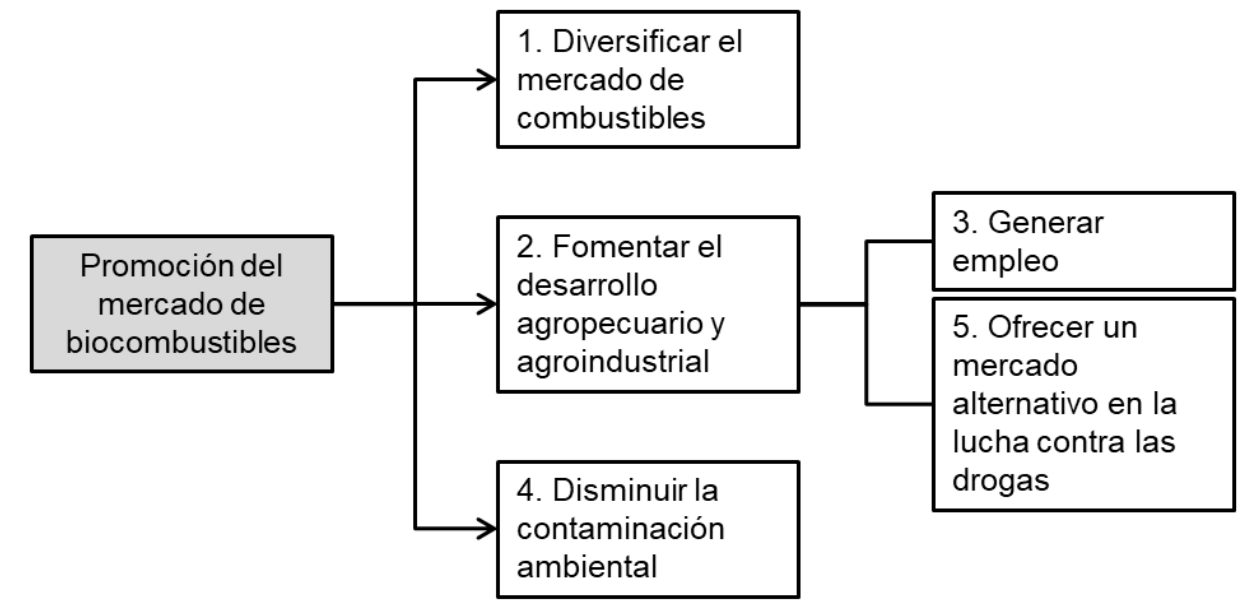

Fuente: elaboración propia

Objetivo 1: diversificar el mercado de combustibles

Tal como se aprecia en la tabla 2, el mercado de combustibles en Perú está compuesto principalmente por los combustibles líquidos, entre los que se encuentran el gasohol, mezcla de gasolina con 7,8 \% de bioetanol. El consumo de gasoholes representó el 11,2\% del consumo de combustibles en el 2017. Si bien es cierto que 
el contenido de bioetanol en los gasoholes es de 7,8 \% en términos volumétricos, en términos de energía es solo de 5,5\% debido al menor poder calorífico del biocombustible con respecto a las gasolinas' ${ }^{1}$ Si se tiene esto en cuenta, el consumo de bioetanol representó el 0,6\% del consumo total de combustibles en Perú durante ese año. Los cálculos para los dos años previos dan resultados similares a 0,6 \%. En consecuencia, la obligatoriedad del uso del bioetanol sí ha generado una diversificación del mercado de combustibles en el Perú, aunque ha sido muy pequeña.

Tabla 2. Perú: consumo final de combustibles, 2016-2017

\begin{tabular}{|c|c|c|c|c|}
\hline \multirow{2}{*}{ Combustibles } & \multicolumn{2}{|c|}{ Terajoule (TJ) } & \multicolumn{2}{|c|}{ Porcentaje (\%) } \\
\hline & 2016 & 2017 & 2016 & 2017 \\
\hline Líquidos & 443.316 & 448.085 & 66,8 & 67,4 \\
\hline Diésel B5 & 227.524 & 224.052 & 34,3 & 33,7 \\
\hline Gas licuado & 79.352 & 82.800 & 12,0 & 12,5 \\
\hline Gasohol & 71.982 & 74.488 & 10,9 & 11,2 \\
\hline Kerosene-Jet & 43.449 & 44.215 & 6,5 & 6,6 \\
\hline Gasolina motor & 11.699 & 12.461 & 1,8 & 1,9 \\
\hline Petróleo industrial & 9.310 & 10.069 & 1,4 & 1,5 \\
\hline Sólidos & 138.597 & 127.403 & 20,9 & 19,2 \\
\hline Leña & 95.675 & 90.430 & 14,4 & 13,6 \\
\hline Carbón mineral & 23.286 & 19.899 & 3,5 & 3,0 \\
\hline Bagazo & 6.575 & 5.301 & 1,0 & 0,8 \\
\hline Bosta y yareta & 5.967 & 5.269 & 0,9 & 0,8 \\
\hline Coque & 2.478 & 2.111 & 0,4 & 0,3 \\
\hline Carbón vegetal & 4.616 & 4.393 & 0,7 & 0,7 \\
\hline Gaseosos & 81.455 & 89.551 & 12,3 & 13,5 \\
\hline Gas distribuido & 81.455 & 89.551 & 12,3 & 13,5 \\
\hline Gas industrial & 0 & 0 & 0,0 & 0,0 \\
\hline Total & 663.368 & 665.039 & 100,0 & 100,0 \\
\hline
\end{tabular}

Fuente: elaboración propia con base en MEM (2018a)

1 Según el MEM (2018a), los poderes caloríficos de la gasolina motor y del bioetanol son de 32,11 y 21,28 $\mathrm{TJ} / 10^{3} \mathrm{~m}^{3}$ respectivamente. Así, el poder calorífico del gasohol con un 7,8\% de volumen de bioetanol es de $31,26 \mathrm{TJ} / 10^{3} \mathrm{~m}^{3}$. 
Objetivos 2, 3 y 5: fomentar el desarrollo agropecuario y agroindustrial, generar empleo y ofrecer un mercado alternativo para cultivos ilícitos

Para evaluar el objetivo de fomentar el desarrollo agropecuario y agroindustrial se estudia el desarrollo de la capacidad productiva de bioetanol combustible realizada a través de la implementación de proyectos de inversión. Para el 2008 ya se habían anunciado ocho proyectos en la costa y selva peruanas con capacidades de producción equivalentes a 24.000 barriles por día calendario (MBDC), según Castro, Sevilla y Coello (2008). Al poner la cifra en contexto, equivale a más de siete veces la demanda nacional de bioetanol combustible registrada en el 2019, como se presenta en el gráfico 8 .

Gráfico 8. Perú: demanda nacional de bioetanol combustible, 2010-2019

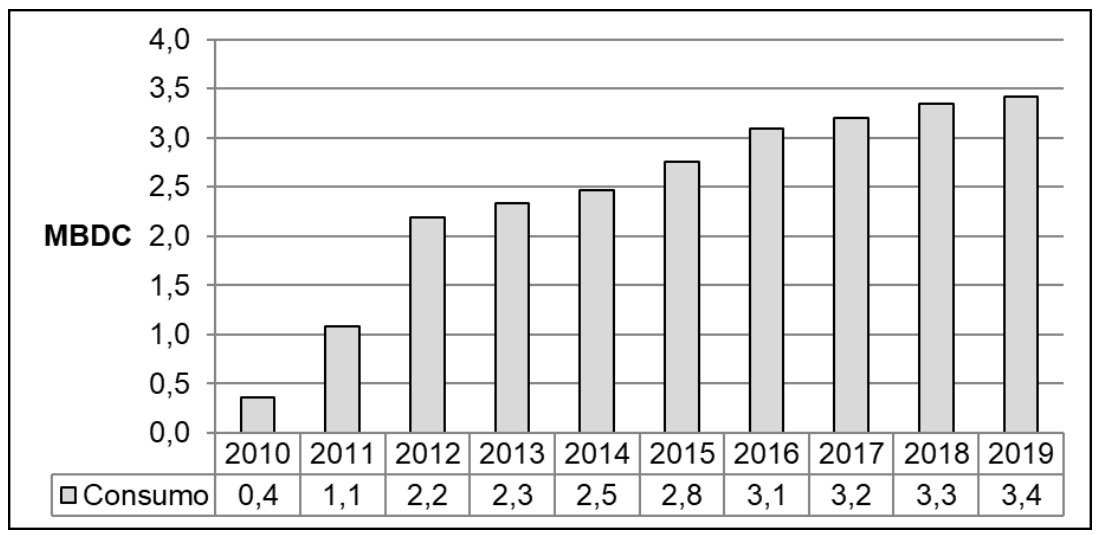

Fuente: elaboración propia con base en MEM (2012; 2018b; 2019)

A pesar de lo expuesto, los proyectos implementados fueron solo dos plantas productoras de bioetanol combustible a partir de caña de azúcar, pertenecientes a Sucroalcolera del Chira S.A., y Maple Etanol S.R.L. Según lo reportado por el MEM (2015), Sucroalcolera del Chira parte del proyecto Caña Brava, empezó a producir en 2009 con una capacidad de producción equivalente a 2,2 MBDC de bioetanol combustible. Posteriormente, en 2012 Maple Etanol inició operaciones con una capacidad de 2,5 MBDC del mencionado producto. Sin embargo, a fines de 2014 Maple Etanol declaró su incapacidad de pagar sus deudas y tuvo que vender sus activos, de acuerdo con lo informado por El Comercio (2015). La planta pasó a ser propiedad de Agrojibito S.A., y la producción de bioetanol combustible cesó. Ya en el 2018, Agrojibito reinició la producción de ese producto e incluso registró exportaciones equivalentes a 69.000 barriles, de acuerdo con las cifras de la Superintendencia Nacional de Aduanas y de Administración Tributaria (Sunat) (2009-2019), como se muestra en el gráfico 9 en el cual se puede apreciar que también exporta bioetanol 
sin desnaturalizar. Las exportaciones de Sucroalcolera del Chira se encuentran en el gráfico 10 .

Gráfico 9. Maple Etanol S.R.L., y Agrojibito S.A.: exportaciones de bioetanol, 2012-2019

\begin{tabular}{|c|c|c|c|c|c|c|c|c|c|}
\hline \multirow{6}{*}{$\begin{array}{l}\text { Miles de } \\
\text { barriles }\end{array}$} & \multicolumn{9}{|l|}{500} \\
\hline & \multicolumn{9}{|l|}{400} \\
\hline & \multicolumn{9}{|l|}{300} \\
\hline & 200 & & & & & & & & \\
\hline & 100 & & & & & & & & \\
\hline & 0 & 2012 & 2013 & 2014 & 2015 & $\begin{array}{rl}1 & 1 \\
2016\end{array}$ & 2017 & 2018 & 2019 \\
\hline $\begin{array}{r}\text { Bioetanol comb } \\
\text { (desnaturaliz }\end{array}$ & $\begin{array}{l}\text { Istible } \\
\text { do) }\end{array}$ & 0 & 0 & 0 & 0 & 0 & 0 & 69 & 0 \\
\hline $\begin{array}{l}\square \text { Bioetanol sin } \\
\text { desnaturalizar }\end{array}$ & & 184 & 434 & 185 & 73 & 60 & 87 & 261 & 312 \\
\hline Total & & 184 & 434 & 185 & 73 & 60 & 87 & 330 & 312 \\
\hline
\end{tabular}

Fuente: elaboración propia con base en Sunat (2009-2019).

Gráfico 10. Sucroalcolera del Chira S.A.: exportaciones de bioetanol, 2012-2019

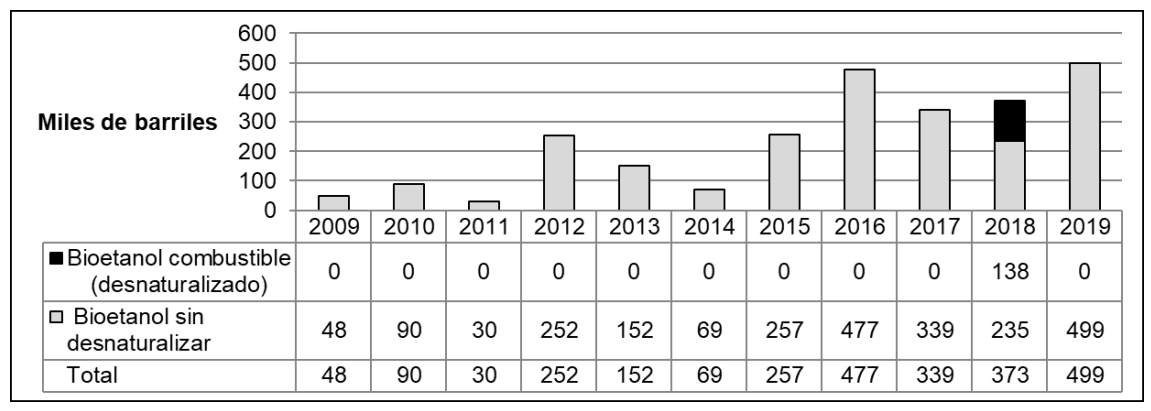

Fuente: elaboración propia con base en Sunat (2009-2019).

Por lo expuesto, Caña Brava es el principal productor de bioetanol combustible en Perú. El proyecto habría generado aproximadamente 1.500 puestos de trabajo directos. Por su parte, la antigua planta de Maple Etanol ahora operada por Agrojibito, habría generado al menos 1.000 puestos de trabajo directos, según lo expuesto por el Ministerio de Agricultura y Riego (Minag) (s. f.). Cabe precisar que la interrupción de la producción de bioetanol combustible no significó un despido masivo porque se siguió cultivando caña de azúcar para otros fines. Por lo tanto, la política pública sí ha cumplido con el objetivo de generar empleo, aunque en suma, solo equivale al 0,3 \% de la población económicamente activa (PEA) del ámbito geográfico en el que se desarrollan: el departamento de Piura y el 0,01 \% de la PEA total peruana, ambas cifras corresponden al 2018, calculadas a partir de los datos del Instituto Nacional de Estadística e Informática (INEI) (2019). 
Las plantas operadas por Caña Brava y Agrojibito se encuentran ubicadas en el departamento de Piura en la costa peruana, no en zonas en las que se realizan cultivos ilícitos, según la Oficina de las Naciones Unidas contra la Droga y el Delito (UNODC) (2018). En ese sentido, la política pública con respecto al bioetanol no ha contribuido con el cumplimiento del objetivo de ofrecer un mercado alternativo en la lucha contra las drogas según el planteamiento gubernamental, es decir, a través de cultivos alternativos.

Como ya se expuso, parte de la justificación de la política de los biocombustibles en Perú se basaba en la generación de capacidad de producción que abastezca la demanda creada por la obligatoriedad de su uso, con los potenciales beneficios que traería esta situación. A pesar de ello, en la realidad el mercado interno se abastece en gran mayoría de productos importados, tal como lo advierte Gutiérrez (2018). El gráfico 11 presenta el caso del bioetanol. Al 2019, el $96 \%$ del consumo interno lo cubrían importaciones de bioetanol.

Gráfico 11. Perú: importaciones de bioetanol para su uso como combustible, 2010-2019

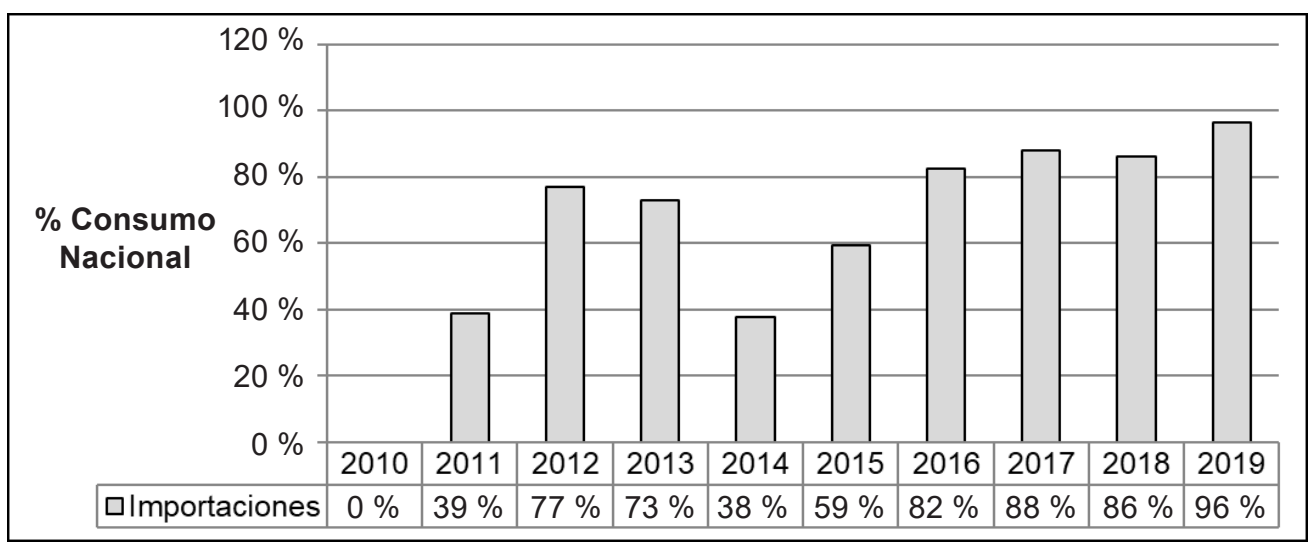

Fuente: elaboración propia con base en MEM (2012; 2018b; 2019) y Sunat (2009-2019)

Según la información de Sunat (2009-2019), los principales importadores de bioetanol para su uso como combustible adquieren el producto de Estados Unidos. Según el Instituto Nacional de Defensa de la Competencia y de la Protección de la Propiedad Intelectual (Indecopi) (2018), las importaciones de bioetanol originario de dicho país tienen precios subvaluados, por lo que se les impuso derechos compensatorios definitivos. La competencia desleal sería la razón por la cual los productores nacionales no pueden abastecer el mercado nacional al no poder ofrecer precios menores. 
Gráfico 12. Perú: importaciones de bioetanol para su uso como combustible, 2010-2019

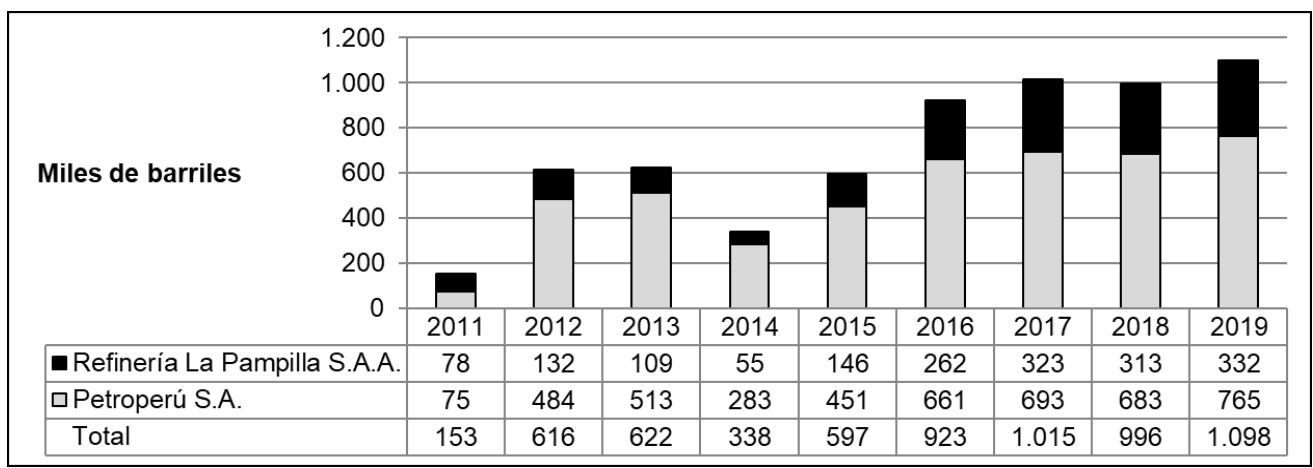

Fuente: elaboración propia con base en Sunat (2009-2019)

\section{Objetivo 4: Disminuir la contaminación ambiental}

La evaluación de la reducción de la contaminación ambiental se basa en una estimación de la reducción de emisiones asociada al empleo de biocombustibles para el 2016. Las estimaciones se realizaron con los factores de emisión de combustibles considerados por el Ministerio del Ambiente (Minam) (2013), los consumos de combustibles registrados por el MEM (2018b) y las emisiones reportadas por el MEM (2017). Los resultados se resumen en la tabla 3. El impacto del uso del bioetanol combustible es positivo en la reducción de contaminantes asociados al uso y transformación de energía, aunque poco significativo. Por lo tanto, el objetivo de reducir las emisiones sí se ha cumplido.

Tabla 3. Perú: estimación de la reducción de emisiones contaminantes por el uso de bioetanol, 2016

\begin{tabular}{l|c|c}
\hline \multicolumn{1}{c|}{ Contaminante } & Índice de toxicidad humana & $\begin{array}{c}\text { Reducción (\% de emisiones por uso } \\
\text { y transformación de energía) }\end{array}$ \\
\hline Óxidos de nitrógeno $\left(\mathrm{NO}_{\mathrm{x}}\right)$ & 1,00 & $-0,09$ \\
\hline Monóxido de carbono $(\mathrm{CO})$ & 0,26 & $-0,22$ \\
\hline Óxidos de azufre $\left(\mathrm{SO}_{\mathrm{x}}\right)$ & 4,00 & $-0,56$ \\
\hline Material particulado $(\mathrm{PM})$ & 4,30 & $+0,00$ \\
\hline
\end{tabular}

Fuente: elaboración propia con base en Minam (2013) y MEM (2017; 2018b)

Luego de haber verificado los objetivos, se evalúan otros impactos en los destinatarios de la política. En este punto se trata de impactos potenciales de la política 
pública sobre el bioetanol en el sector agrícola como destinatario de esta última.

La Organización de las Naciones Unidas (ONU) (2007) advierte sobre dos potenciales problemas relacionados con el sector agrícola. El primer problema es la concentración de la propiedad de las tierras de cultivo en la búsqueda de economías de escala, lo que favorecería a los grandes productores en perjuicio de los pequeños. El segundo problema es consecuencia del incremento de la demanda de tierra, agua y otros recursos para el cultivo de materias primas para la producción de biocombustibles. El incremento de la demanda de tierras incrementaría el precio de las tierras para cultivos con fines diferentes a la producción de biocombustibles. Por otro lado, la mayor demanda de agua podría generar conflictos sociales en las zonas donde este recurso es escaso.

\subsection{Efectos colaterales de la política en otras situaciones y grupos}

Se han determinado efectos colaterales en el ingreso fiscal y en la emisión de gases de efecto invernadero. De igual manera, se consideran otros impactos potenciales en el ambiente y la seguridad alimentaria.

\section{Ingreso fiscal}

La implementación de la obligatoriedad del uso del bioetanol combustible estuvo acompañada por una diferenciación del Impuesto Selectivo al Consumo (ISC) aplicado a las gasolinas y a los gasoholes. La Sunat (s.f.) precisa que el ISC es un impuesto indirecto que grava bienes que producen impactos negativos de carácter individual, social y medioambiental, como es el caso de los combustibles.

El ISC de los combustibles se determina al evaluar su grado de nocividad para la salud pública, según el CRP (2006). Al considerar que los gasoholes son menos nocivos para la salud que las gasolinas, su ISC es menor. Esto trae como consecuencia menores ingresos fiscales por concepto de ISC. Con los consumos de gasoholes registrados por el MEM (2019) y los valores del ISC establecidos por el Poder Ejecutivo del Perú (PEP) (2014; 2018), se estima una disminución del ingreso fiscal de 34,0 millones de soles, equivalente a 10,3 millones de dólares americanos para el 2018.

\section{Emisión de gases de efecto invernadero (GEI)}

Las emisiones de GEI son las causantes del calentamiento global. Por ello, una de las ventajas más divulgadas del consumo del bioetanol combustible es la menor 
emisión de GEI con respecto a las gasolinas. La ONU (2007) sostiene que se deben cuantificar las emisiones mediante un balance que considere todo el ciclo de vida, desde la producción hasta el consumo.

Quispe et al., (2009) evalúan las emisiones de GEI durante el ciclo de vida del bioetanol combustible producido en Perú y las comparan con las del ciclo de vida de los combustibles fósiles. Los autores consideran como un escenario el ciclo de vida del bioetanol combustible producido en terrenos eriazos de la costa norte peruana a partir del cultivo de caña de azúcar y concluyen que su impacto ambiental es menor que el de las gasolinas, aproximadamente $26 \%$ menos emisiones de GEI. Por su parte, cuando se evalúa el ciclo de vida del gasohol con 7,8 \% de bioetanol combustible, que es el caso peruano, las emisiones son solo 3,7 \% menores. Sin embargo, estos cálculos se realizaron puesto que el bioetanol utilizado en la mezcla era de origen peruano. Dado que el mercado peruano se abastece principalmente con bioetanol combustible importado, cuyo ciclo de vida se desconoce, además del efecto del balance de GEI del bioetanol combustible exportado desde Perú, no es posible calcular la variación exacta de las emisiones de GEI atribuibles al uso de bioetanol combustible en Perú. Por ende, la política pública sobre el bioetanol combustible parece haber tenido un impacto positivo en la reducción de GEI, aunque no es posible cuantificarlo.

\section{Otros impactos potenciales}

La ONU (2007) considera como impactos potenciales otros aspectos ambientales y de seguridad alimentaria. Con respecto a los daños al ambiente se incluyen: deforestación, pérdida de biodiversidad y erosión de los suelos. Por otro lado, la seguridad alimentaria se podría ver afectada negativamente como producto de la menor disponibilidad de tierras, agua y otros recursos utilizados para el cultivo de alimentos, además del incremento de los precios de los alimentos básicos, lo que perjudicaría su accesibilidad por parte de los más pobres.

Al 2019, el bioetanol combustible en Perú se produce a base de caña de azúcar cultivada en tierras eriazas, por lo que los impactos ambientales son mínimos y no se ha visto afectada la disponibilidad de tierras, pero sí la de agua. Sobre el último punto, luego de un estudio detallado en la costa norte del Perú, Lizana (2016, p. 198) concluyó que "el cultivo de caña de azúcar, como materia prima para la producción de bioetanol, no representa amenaza o riesgo para la utilización del agua en el desarrollo de actividades agrícolas". De igual manera, concluyó que la seguridad alimentaria no se ha visto afectada. Pese a lo anterior y dada su importancia, los aspectos mencionados se deben tomar en cuenta en proyectos futuros. 


\section{PROPUESTA DE CAMBIOS EN LA POLÍTICA PÚBLICA DEL BIOETANOL COMBUSTIBLE}

\subsection{Los objetivos de la política pública}

Lo primero que se debe tener en cuenta es la pertinencia de los objetivos con respecto a la coyuntura global. Tal como se sostuvo con anterioridad, para el IICA (2007) la promoción de la producción y uso de biocombustibles responde a tres problemas de alcance global: (a) el agotamiento de los combustibles fósiles, (b) el calentamiento global y (c) la contaminación ambiental. No obstante, solo dos de los objetivos planteados por el gobierno peruano se alinean con la perspectiva global: diversificar el mercado de combustibles y disminuir la contaminación ambiental. Los otros tres objetivos responden a un interés nacional. Por otra parte, no se tomó en cuenta el problema del calentamiento global cuando se plantearon los objetivos.

En este punto, se propone mantener los cinco objetivos porque pretenden contribuir con la mitigación de problemas de alcance nacional y global. Sin embargo, se debe formalizar el objetivo de reducir el calentamiento global.

El otro tema con respecto a los objetivos de la política sobre el bioetanol es su conflicto con los objetivos de otras políticas. El principal conflicto se da con la masificación del gas natural. Según el MEM (2014), la política de masificación del gas natural haría que su consumo desplace progresivamente el consumo de gasolinas y en consecuencia, el de gasoholes. En la tabla 4 es posible notar el objetivo de incrementar la participación del gas natural y reducir la de las gasolinas y gasoholes, cuyo consumo disminuiría en 2,0 \% promedio anual en el periodo 2014-2025, según el MEM (2014).

Tabla 4. Perú: estructura del consumo final de energía por fuentes según el Plan Energético Nacional 2014-2025

\begin{tabular}{|c|c|c|}
\hline Fuente & 2014 (\%) & $\begin{array}{c}2025 \text { - Escenario con } \\
\text { crecimiento del PBI de 4,5\% } \\
\text { (\%) }\end{array}$ \\
\hline Electricidad & 19 & 18 \\
\hline Gas natural & 13 & 35 \\
\hline Diesel & 28 & 19 \\
\hline GLP & 10 & 12 \\
\hline Gasolina motor & 8 & 4 \\
\hline
\end{tabular}




\begin{tabular}{|c|c|c|}
\hline Fuente & $2014(\%)$ & $\begin{array}{c}2025 \text { - Escenario con } \\
\text { crecimiento del PBI de } 4,5 \% \\
\text { (\%) }\end{array}$ \\
\hline Turbo & 5 & 4 \\
\hline Petróleo industrial & 2 & 0 \\
\hline Carbón mineral y dervivados & 3 & 3 \\
\hline Bosta y yareta & 1 & 1 \\
\hline Dendroenergía $(*)$ & 11 & 4 \\
\hline Total & 100 & 100 \\
\hline
\end{tabular}

(*) Incluye leña, carbón vegetal y bagazo.

Fuente: MEM (2014)

El objetivo implícito de reducir el consumo de gasoholes entra en conflicto con la política de promoción del bioetanol combustible. En ese sentido, si bien el uso del gas natural contribuye a reducir las emisiones que dañan el ambiente cuando se comparan con el uso de las gasolinas, el gas natural -tal como el petróleo crudo- es una fuente no renovable de energía. Pese a lo expuesto, el consumo de gasoholes no se ha reducido en el periodo 2014-2019, sino que ha tenido un incremento sostenido, como se puede observar en el gráfico 13.

Gráfico 13. Perú: consumo de gasoholes y gasolinas, 2010-2019

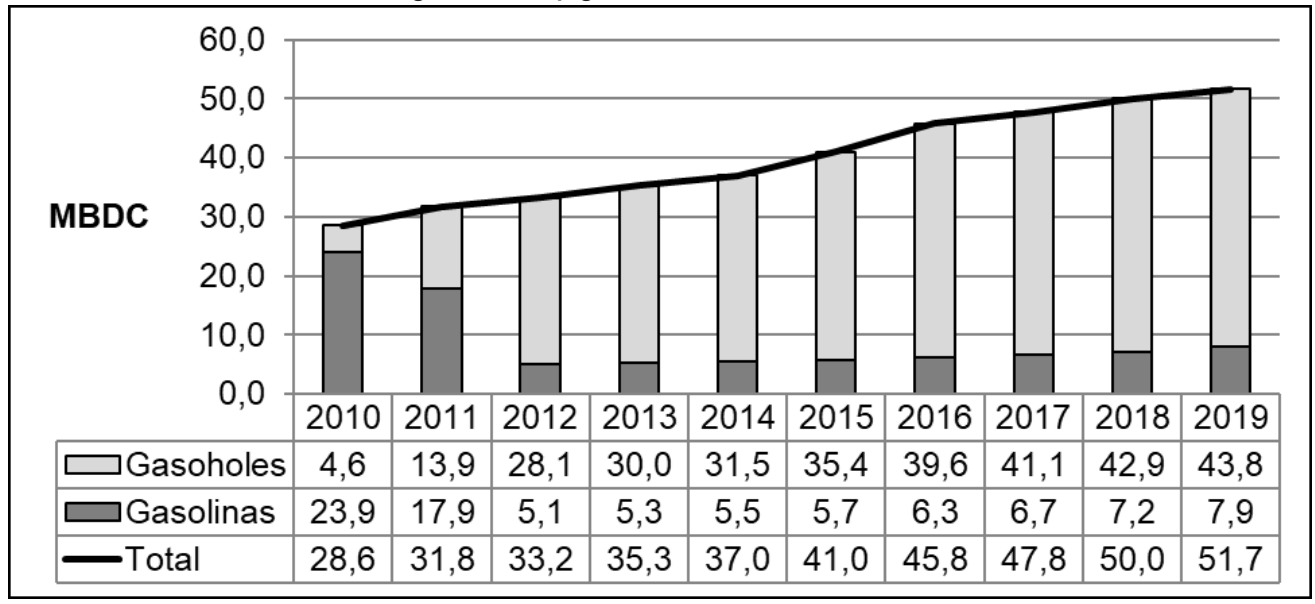

Fuente: elaboración propia

En consecuencia, se debe revisar la política de masificación del gas natural y su relación con la política de promoción del bioetanol. 


\subsection{El modelo causal}

El modelo causal de la política pública sobre el bioetanol combustible se construyó a partir de la interpretación de las acciones gubernamentales y herramientas políticas aplicadas. El diagrama de relaciones causales se muestra en el gráfico 14.

Gráfico 14. Perú: modelo causal de la política pública sobre el bioetanol combustible, 2003-2019

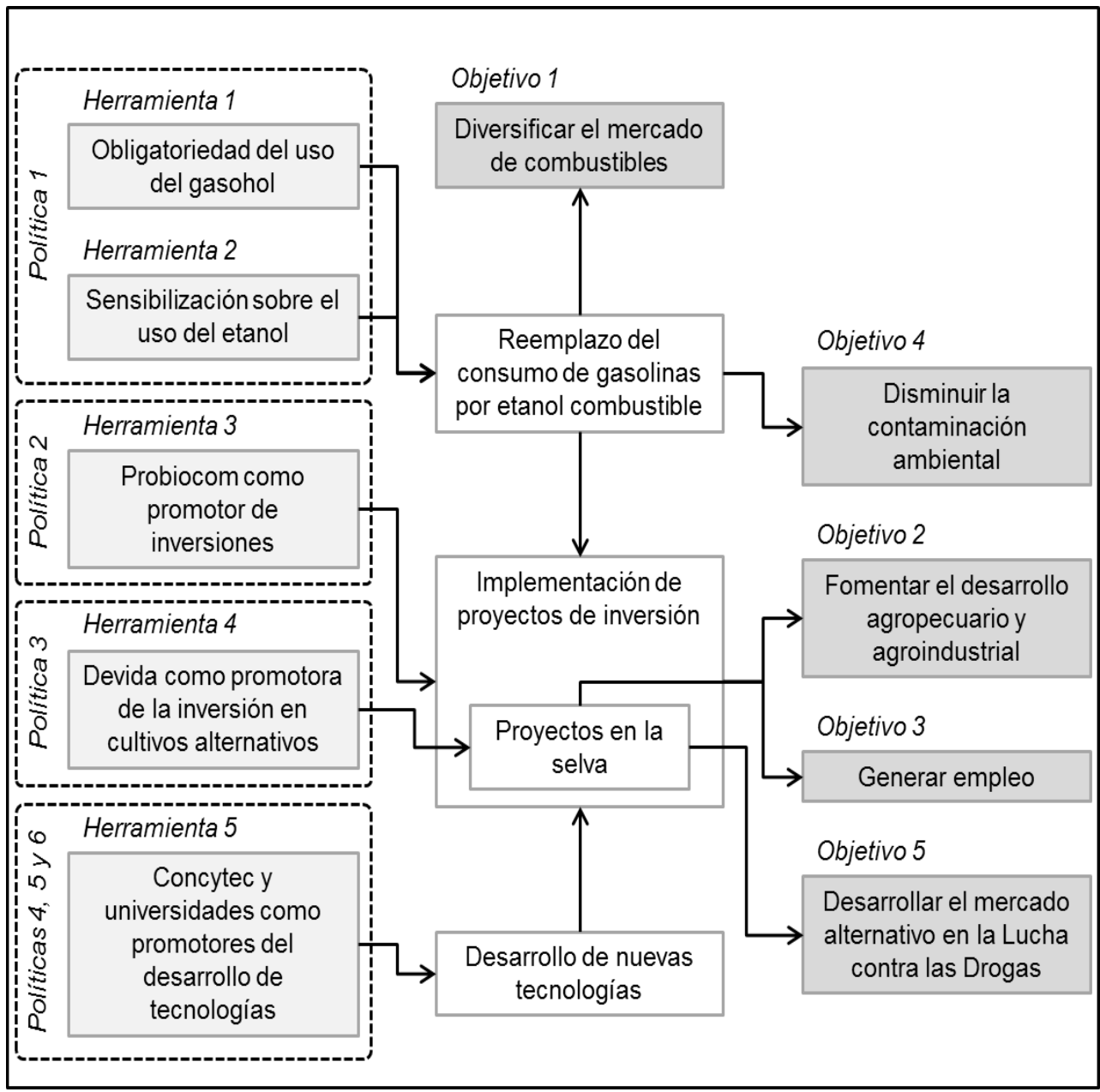

Fuente: elaboración propia

El principal problema del modelo causal utilizado es la relación esperada entre las organizaciones y la implementación efectiva de proyectos de inversión, los cuales no se han desarrollado según las expectativas. Los promotores de inversiones no son suficientes para asegurar las inversiones en biocombustibles dada la naturaleza multisectorial del tema. 


\subsection{Las herramientas de la política pública}

Herramienta 1: obligatoriedad de uso del gasohol

Conforme a lo establecido por el PEP (2007), esta medida establece el uso obligatorio de los gasoholes, es decir, las gasolinas mezcladas con bioetanol combustible en un porcentaje de $7,8 \%$ del volumen total. Asimismo, establece exclusividad mediante la prohibición de la venta de gasolinas en los lugares en los que se implementó la obligatoriedad del uso del gasohol. El cronograma de aplicación fue progresivo hasta el $1^{\circ}$ de diciembre de 2011 para todos los departamentos, excepto los amazónicos: Amazonas, San Martín, Loreto, Ucayali y Madre de Dios.

La medida buscaba reemplazar el 7,8 \% del consumo de gasolinas por bioetanol combustible. A través de la Ley n. 28054 el CRP (2003) creó una comisión técnica para proponer el porcentaje de bioetanol combustible en los gasoholes. Según el Conam (2004), la comisión técnica concluyó que el porcentaje máximo técnicamente viable de bioetanol combustible era 7,8 \% del volumen total, el cual estaba acorde con las condiciones del parque automotor del 2004. Empero, reconoció que los principales fabricantes de vehículos aceptaban la posibilidad de utilizar hasta $10 \%$ de bioetanol combustible sin modificar los motores. Al 2019, se debería evaluar la pertinencia de modificar el porcentaje de bioetanol combustible en los gasoholes debido al cambio que han tenido las condiciones del parque automotor peruano.

Por otra parte, se deben estudiar los supuestos que llevaron a la decisión de no hacer extensiva la obligatoriedad del uso del gasohol a los departamentos amazónicos, sobre todo porque la demanda de gasoholes se ha extendido de manera natural a San Martín, Ucayali y Amazonas, aunque con una participación muy pequeña equivalente a 0,5\% del consumo total de los departamentos amazónicos en el periodo 2012-2018, según el Organismo Supervisor de la Inversión en Energía y Minería (Osinergmin) (2012-2018).

\section{Herramienta 2: sensibilización sobre el uso del bioetanol}

De acuerdo con el CRP (2003), la comisión técnica creada por la Ley n. 28054 tenía como encargo proponer un programa de sensibilización con respecto al uso de bioetanol combustible, dirigido a los consumidores e instituciones públicas. Debido a las condiciones de obligatoriedad y exclusividad de venta de los gasoholes, los consumidores finales de gasolinas no tenían otra opción más que comprar gasoholes por la falta de productos sustitutos inmediatos. Entonces, para el caso de los consumidores la sensibilización era de carácter informativo mas no persuasivo, con el fin de incentivar su consumo. 
Al 2019, un nuevo programa de sensibilización se hace innecesario dado que su finalidad era informar a los usuarios durante la implementación de la obligatoriedad del uso de los gasoholes.

\section{Herramienta 3: el Probiocom como promotor de inversiones en biocombustibles}

Según el CRP (2003), mediante la Ley n. 28054 se creó el Probiocom a cargo de Proinversión, con el objeto de promover las inversiones en biocombustibles y difundir las ventajas de su utilización. Sin embargo, las inversiones en bioetanol combustible se limitaron a dos proyectos de los muchos anunciados.

Como ya se mencionó, la promoción de biocombustibles no es solo un tema de inversión privada sino que compromete varios sectores, entre los que destacan: energía, agricultura, producción y ambiente. Bajo esta premisa, en el 2009 se creó la Comisión Multisectorial sobre Bioenergía (CMB), mediante D.S. n. ${ }^{\circ}$ 075-2009-PMC. Según el PEP (2009b, p. 2), la CMB es de naturaleza permanente y su objeto es "evaluar y recomendar medidas que promuevan la gestión integral de la bioenergía a nivel nacional".

La CMB (2011) puso en discusión la necesidad de un mecanismo articulador único del mercado de biocombustibles y propuso que el Probiocom pasara a formar parte de la CMB. El tema no se agendó y por el contrario, la CMB fue extinta en el 2017 con el argumento de que las actividades relacionadas a bioenergía las deberían desarrollar grupos de trabajo existentes, por ello la CMB era innecesaria, tal como sostuvo el PEP (2017) en su momento.

El poco éxito de esta herramienta radica en supuestos erróneos sobre el comportamiento esperado de los destinatarios de la política, puesto que el Probiocom por sí solo no es suficiente para lograr las inversiones esperadas. Se propone crear una comisión multisectorial como organismo articulador del mercado de biocombustibles e incluir al Probiocom dentro su estructura.

\section{Herramienta 4: Devida como promotora de la inversión en cultivos alternativos}

La Comisión Nacional para el Desarrollo y Vida sin Drogas (Devida) fue designada por la Ley n. 28054 como promotora de la inversión privada en cultivos alternativos a aquellos con fines ilícitos. De acuerdo con el PEP (2007), se le asignaron funciones a Devida para promover proyectos de producción de biocombustibles en zonas en las cuales se requiera sustituir cultivos ilícitos. En la práctica, esto únicamente significó la inclusión de los biocombustibles en el portafolio de cultivos alternativos como el café y el cacao, puesto que Devida no cuenta con ninguna dependencia encargada exclusivamente de los biocombustibles. 
Al 2017, según información de Minag (2018), el 74 \% de la superficie cosechada de caña de azúcar para la producción de bioetanol no combustible estaba ubicada en los departamentos en los que se cultiva coca, cuyo mapa se puede observar en el gráfico 15. Esto significa que el cultivo de caña de azúcar para bioetanol combustible podría ser un cultivo alternativo que requiere fomento por parte de Devida.

Gráfico 15. Perú: mapa de superficie cosechada de caña de azúcar para bioetanol no combustible y zonas de cultivo de coca, 2017

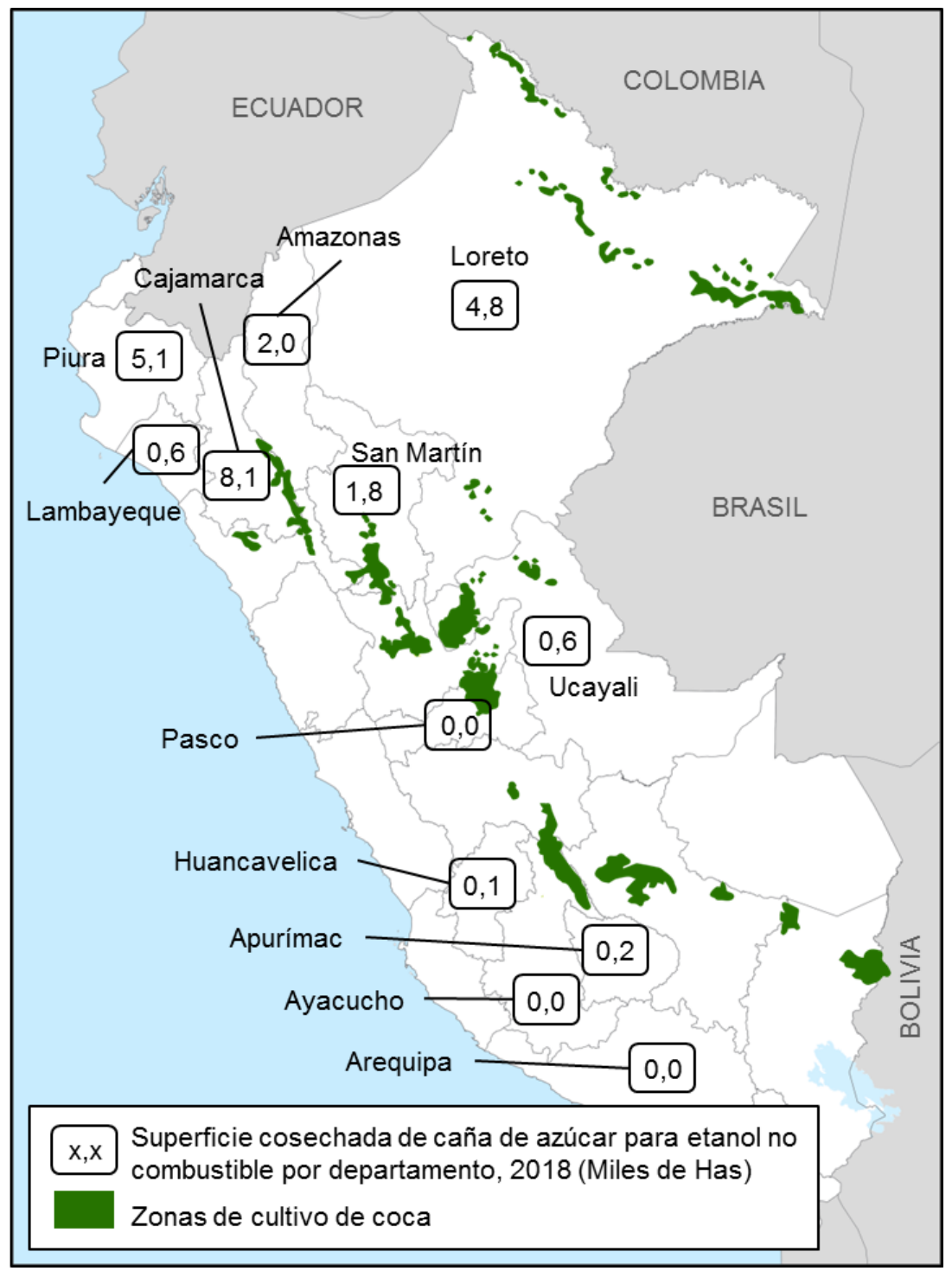

Fuente: elaboración propia con base en Minag (2018) y UNODC (2018) 
De la misma manera que el Probiocom, el problema de Devida es que por sí sola no es suficiente para lograr las inversiones esperadas. Se evidencian problemas en la organización e infraestructura para el logro de sus objetivos relacionados con biocombustibles. Por lo tanto, se propone la formación de una dependencia en Devida que trate exclusivamente el tema de biocombustibles para poder obtener resultados relevantes.

Herramienta 5: Concytec y las univer tecnologías

De acuerdo con el PEP (2005), el r • Distribuidores Nacional de Ciencia y Tecnología mayoristas versidades como promotores del • Establecimientos de los biocombustibles.

\section{- Refinerías Plantas de venta al público Consumidores finales}

res del desarrollo de

7. 28054 designó al Consejo ógica (Concytec) y a las unitecnologías en la cadena de

El Concytec incluyó a los biocombustibles dentro de los sectores productivos prioritarios del Plan Nacional Estratégico de Ciencia, Tecnología e Innovación para la Competitividad y el Desarrollo Humano 2006-2021, según Concytec (2006). Después de ello, el tema de los biocombustibles se integró en una de las áreas temáticas de investigación de su Programa Nacional Transversal de Biotecnología 2016-2021, de acuerdo con Concytec (2016).

La CMB (2010) sostuvo que Concytec tiene un presupuesto muy limitado y no cuenta con una partida específica para el financiamiento de investigaciones sobre biocombustibles. Por otro lado, reconoció que varias universidades realizan investigaciones relacionadas con los biocombustibles, pero sus objetivos no están coordinados.

Esta herramienta tiene problemas con la disponibilidad de recursos para implementar la política. Por un lado está la falta de recursos financieros y por el otro, presenta organización e infraestructura deficientes.

Se propone formar un programa especial financiado que gestione la investigación de las universidades para que persigan un objetivo común y sus resultados sean de utilidad práctica. Este punto es de especial importancia puesto que cada decisión tomada sobre el tema de biocombustibles se debería basar en investigaciones aplicadas a la realidad peruana, y debido a la relevancia de la investigación en el desarrollo de biocombustibles cuya materia prima no compita con la producción de alimentos, los denominados biocombustibles de segunda y tercera generación. Por su parte, el organismo articulador del mercado de biocombustibles debería tener como tarea lograr una conexión eficiente y efectiva entre empresa privada y 
centros de investigación.

\subsection{Los destinatarios de la política pública}

El gráfico 16 muestra las personas y organizaciones cuyo comportamiento se pretende alterar con la política pública sobre el bioetanol combustible.

Gráfico 16. Perú: destinatarios de la política pública sobre el bioetanol combustible

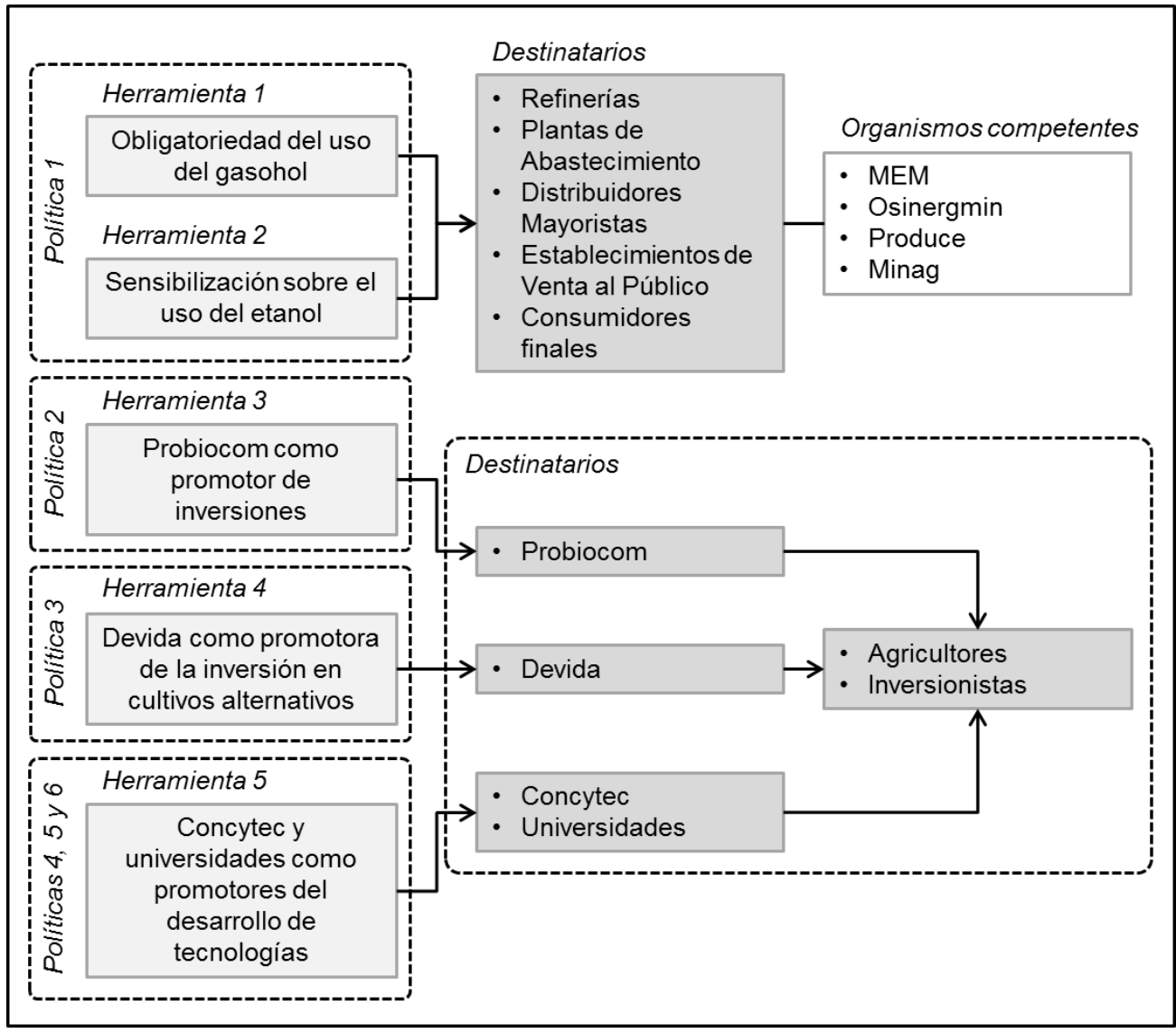

Fuente: elaboración propia con base en CRP (2003) y PEP (2005; 2007; 2008; 2009a; 2010; 2011)

Los destinatarios de la política son los pertinentes, por lo que no se proponen cambios.

\subsection{La implementación de la política pública}

La implementación de la política pública sobre el bioetanol combustible y los biocom- 
bustibles en general, sigue un enfoque de arriba hacia abajo, parte de objetivos claros en el nivel más alto de formuladores de políticas, producto de un estudio preliminar del Grupo Técnico de Biocombustibles, según el Conam (2002). No obstante, se hace necesario considerar las limitaciones de los implementadores de nivel más bajo, como es el caso de Probiocom, Devida, Concytec y las universidades. Por esa razón se propone utilizar un enfoque mixto que tenga en cuenta dichas limitaciones.

A partir de la revisión de los puntos anteriores, se propone el modelo causal representado en el gráfico 17 . Se plantea conservar la mayoría de políticas vigentes e incluir el objetivo de disminuir el calentamiento global, según lo expuesto. Con respecto a las herramientas, se propone reemplazar a Probiocom como promotor de las inversiones por una entidad multisectorial como lo fue la CMB, para que funcione como articuladora del mercado de biocombustibles.

Gráfico 17. Perú: modelo causal propuesto para la política pública sobre el bioetanol combustible

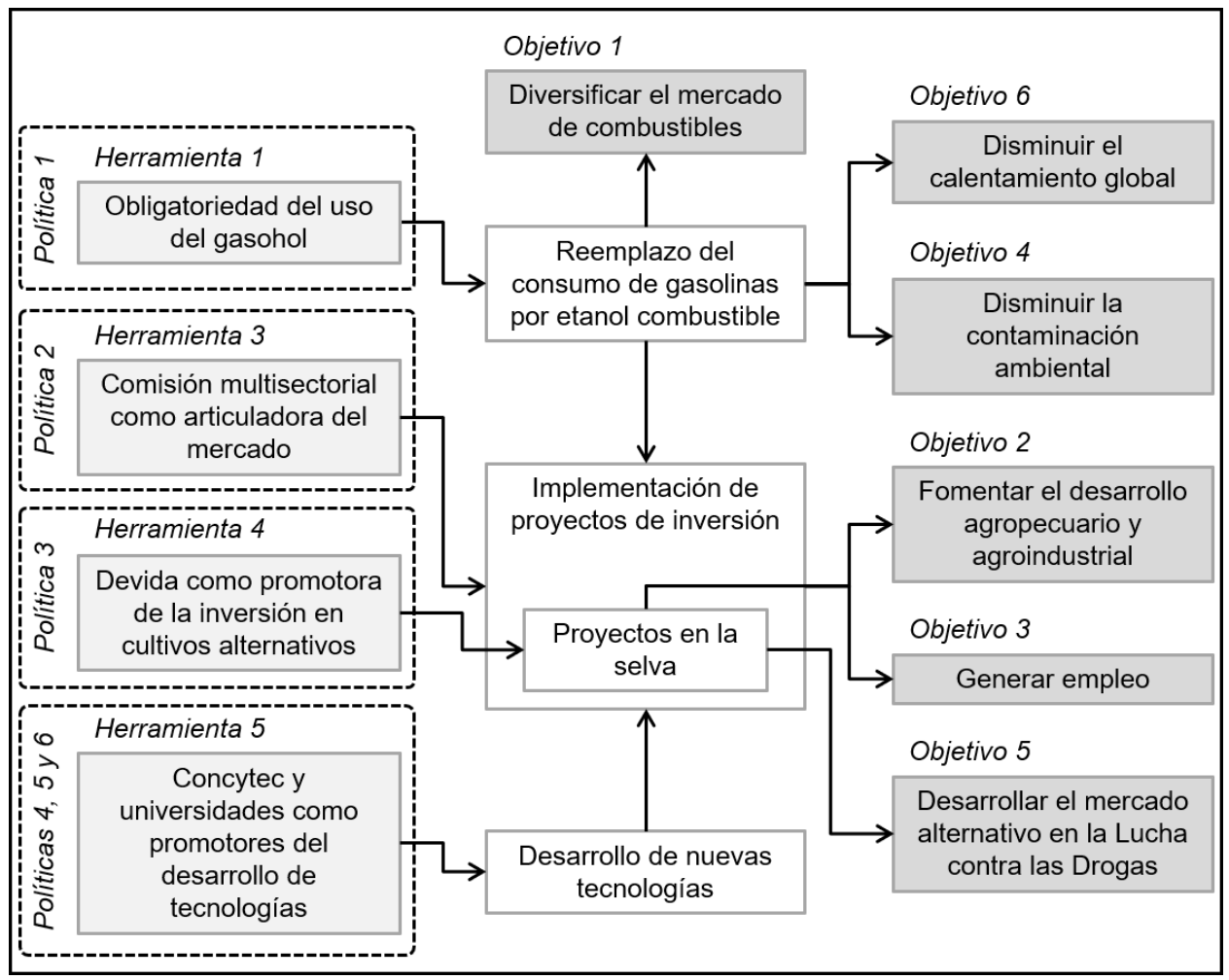

Fuente: elaboración propia

CONCLUSIONES Y RECOMENDACIONES 
La promoción de la producción y uso de los biocombustibles en Perú se basa en políticas generales sobre tres aspectos: (a) comercialización de biocombustibles, (b) inversión privada e (c) investigación y desarrollo tecnológico. Estas políticas se traducen en cinco herramientas: (a) obligatoriedad del uso del gasohol, (b) creación de un programa de sensibilización, (c) creación de Probiocom como promotor de las inversiones en biocombustibles, (d) dotación de funciones a Devida como promotora de inversión en cultivos alternativos y (e) designación de Concytec y las universidades como promotores del desarrollo de nuevas tecnologías.

Sí se cumplieron los objetivos planteados por la política pública, pero con impactos poco relevantes. A falta de objetivos y metas cuantificables, no es posible determinar si se ha cumplido con las expectativas de los formuladores de políticas. Se recomienda cuantificar los objetivos para una mejor evaluación.

La obligatoriedad del uso de bioetanol combustible representó en el periodo 2015-2017 una diversificación del mercado de combustibles equivalente a 0,6 \%.

A pesar de contar con dos plantas de bioetanol combustible que podrían satisfacer la demanda interna, el mercado se abastece principalmente con productos importados. Esto se ocasionaría debido a la competencia desleal que suponen los precios subvaluados de los productos importados desde Estados Unidos, contra los que los productos nacionales no pueden competir.

El uso del bioetanol combustible ha significado una reducción en la emisión de contaminantes, aunque los valores son poco relevantes. En este punto, se recomienda realizar una comparación de las emisiones contaminantes durante los ciclos de vida.

El uso del bioetanol combustible ocasiona una reducción de los ingresos fiscales, estimados en 10,3 millones de dólares americanos para 2018.

La política pública sobre el bioetanol combustible habría tenido un impacto positivo en la disminución de GEI, pero no es posible cuantificarlo.

Los proyectos de producción de bioetanol combustible en marcha no han sido causantes de deforestación, pérdida de biodiversidad o riesgos a la seguridad alimentaria. Sin embargo, estos aspectos se deben tomar en cuenta para futuros proyectos.

Es importante recalcar que la política sobre el uso del bioetanol combustible, y en general sobre los biocombustibles, se debe acompañar de medidas complementarias que apunten a reducir la contaminación ambiental y el calentamiento global, tales como: (a) renovación del parque automotor, (b) fiscalización a las empresas encar- 
gadas de certificar el estado de los vehículos y (c) discusión sobre la introducción de autos eléctricos que funcionen con energía renovable.

La promoción de biocombustibles surgió como respuesta al agotamiento de los combustibles fósiles, el calentamiento global y la contaminación ambiental. En este contexto, la política pública peruana no ha formalizado el objetivo de reducir el calentamiento global y ha incluido objetivos de interés nacional.

La política de promoción de biocombustibles entra en conflicto con la política de masificación del gas natural, la cual busca reducir el consumo de gasoholes y por ende, el de bioetanol combustible. Se recomienda redefinir la política de masificación de gas natural y reconocer limitaciones con respecto al reemplazo de los gasoholes, situación que no se ha dado en la realidad.

Por otra parte, se recomienda revisar la política de masificación del gas natural, no solo en lo relacionado con el reemplazo de los gasoholes, sino también con su uso para la generación eléctrica. El gas natural -al igual que el petróleo crudo- es una fuente no renovable de energía, por lo que se debería migrar hacia fuentes renovables como la eólica, todo ello en pos de una verdadera diversificación de la matriz energética, independizada de los combustibles fósiles.

Los promotores de inversiones, Probiocom y Devida, no son suficientes para asegurar la implementación de proyectos de inversión en biocombustibles debido a la naturaleza multisectorial del tema. Se recomienda evaluar la pertinencia de modificar el porcentaje de bioetanol combustible en los gasoholes al considerar que el parque automotor peruano ha cambiado sus características desde la implementación de la política. Además, se debe evaluar la obligatoriedad del uso del gasohol en los departamentos amazónicos.

Probiocom no tuvo el éxito esperado por falta de un enfoque multisectorial. Por consiguiente, se recomienda crear una comisión multisectorial como organismo articulador del mercado de biocombustibles e incluir a Probiocom dentro su estructura.

Devida ha incluido el tema de biocombustibles como un cultivo alternativo adicional a los que ya manejaba. Por lo tanto, si se quiere obtener resultados relevantes se debería formar una dependencia que trate exclusivamente el tema de biocombustibles.

Concytec carece de una partida presupuestal para el desarrollo de proyectos sobre biocombustibles. Se hace necesario formar un programa especial financiado que gestione la investigación de las universidades para que persigan un objetivo común y sus resultados sean de utilidad práctica. Por su parte, el organismo arti- 
culador del mercado de biocombustibles tendría la tarea de lograr una conexión eficiente y efectiva entre empresa privada y centros de investigación.

Perú cuenta con capacidad productiva de bioetanol hidratado, el cual se podría convertir en bioetanol anhidro para que se utilice como combustible y abastezca al mercado peruano e internacional. Sin embargo, se necesitan medidas adecuadas para promover las inversiones.

\section{REFERENCIAS}

Anderson, James (2010). Public policymaking: An introduction. Boston, Estados Unidos de América: Cengage Learning, 342p.

Bajpai, Pratima (2013). Advances in bioethanol. Nueva Delhi, India: Springer, 96p.

Birkland, Thomas (2011). An introduction to the policy process: Theories, concepts, and models of public policy making. Nueva York, Estados Unidos de América: Routledge, 339p.

Castro, Paula; Sevilla, Susana y Coello, Javier (2008). Estudio sobre la situación de los biocombustibles en el Perú. Lima, Perú: Soluciones Prácticas ITDG, 68p.

Cepal (Comisión Económica para América Latina y el Caribe) (2006). Especificaciones de la calidad del etanol carburante y del gasohol (mezcla de gasolina y etanol) y normas técnicas para la infraestructura. México, México: Cepal, 57p.

CMB (Comisión Multisectorial sobre Bioenergía) (2010). Primer informe técnico sobre investigación y transferencia tecnológica en bioenergía. Perú: Ministerio de Agricultura y Riego.

CMB (Comisión Multisectorial sobre Bioenergía) (2011). Análisis de la cadena de valor del alcohol carburante y del biodiesel. Perú: Ministerio de Agricultura y Riego.

Conam (Consejo Nacional del Ambiente) (2002). Informe: Propuesta para la promoción del uso de biocombustibles líquidos en el Perú. Perú: Presidencia del Consejo de Ministros.

Conam (Consejo Nacional del Ambiente) (2004). Comisión Técnica Ley 28054 promoción del mercado de biocombustibles: Informe final. Perú: Presidencia del Consejo de Ministros.

Concytec (Consejo Nacional de Ciencia y Tecnología e Innovación Tecnológica) (2006). Plan nacional estratégico de ciencia, tecnología e innovación para la competitividad y el desarrollo humano 2006-2021. Lima, Perú: Concytec, 102p.

Concytec (Consejo Nacional de Ciencia y Tecnología e Innovación Tecnológica) (2016). Programa nacional transversal de biotecnología 2016-2021. Lima, Perú: Concytec, 42p.

CRP (Congreso de la República del Perú) (2003). Ley n. 28054. Ley de promoción del mercado de biocombustibles, $3 p$.

CRP (Congreso de la República del Perú) (2006). Ley n. 28694. Ley que regula el contenido de azufre en el combustible diésel, 2p.

Demirbas, Ayhan (2008). Biofuels: Securing the planet's future energy needs. Londres, Reino Unido: Springer, 336p. 
Dunn, William (2007). Public policy analysis: An introduction. Nueva Jersey, Estados Unidos de América: Pearson, 496p.

Dye, Thomas (2013). Understanding Public Policy. London, United Kingdom: Pearson, 368p.

EIA (U.S. Energy Information Administration) (s.f.). Glosario de la EIA. USA: EIA.

El Comercio (2015). Grupo Gloria pagará US \$ 108 millones por activos de etanol de Maple, Negocios, Perú.

FAO (Organización de las Naciones Unidas para la Agricultura y la Alimentación) (2004). Terminología unificada sobre bioenergía: Terminología de los dendrocombustibles sólidos. Roma, Italia: Departamento Forestal de la FAO, 58p.

FAO (Organización de las Naciones Unidas para la Agricultura y la Alimentación) (2008). Bosques y energía: cuestiones clave. Roma, Italia: Estudio FAO Montes, 69p.

Grupo Romero (s.f.). Caña Brava.

Gupta, Ram y Demirbas, Ayhan (2010). Gasoline, diesel, and ethanol biofuels from grasses and plants. Nueva York, Estados Unidos de América: Cambridge University Press, 229p.

Gutiérrez, César (2018). El fracaso de la política de promoción de biocombustibles. Expreso.

Hill, John y Kolb, Doris (1999). Química para el nuevo milenio. México, México: Prentice Hall, 677p.

Howlett, Michael; Mukherjee, Ishani y Woo, Jun Jie (2015). From tools to toolkits in policy design studies: the new design orientation towards policy formulation research. En: Policy and Politics, Vol. 43, N.․ 2, p. 291-311. Doi: 10.1332/147084414X13992869118596

IICA (Instituto Interamericano de Cooperación para la Agricultura) (2007). Atlas de la agroenergía y los biocombustibles en las Américas: i.Etanol. San José, Costa Rica: IICA, 181p.

Indecopi (Instituto Nacional de Defensa de la Competencia y de la Protección de la Propiedad

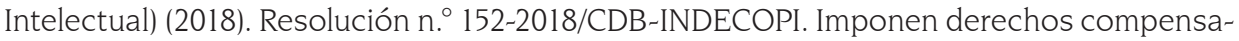
torios definitivos sobre las importaciones de etanol originario de los EE.UU., $6 \mathrm{p}$.

INEI (Instituto Nacional de Estadística e Informática) (2019). Población Económicamente Activa [Archivos de datos]. INEI.

John, Peter (2011). Making policy work. Nueva York, Estados Unidos de América: Routledge, 198p.

Lizana, Víctor (2016). El etanol carburante en la costa norte del Perú. Impactos energético, ambiental y socioeconómico. Tesis para optar al título de Doctor. Doctorado en tecnología, diversificación, calidad y ahorro energético, Universidad de Oviedo, España, 240p.

MEM (Ministerio de Energía y Minas) (2007). Exposición de motivos. Exposición de motivos del decreto supremo que aprueba el reglamento para la comercialización de biocombustibles, $4 \mathrm{p}$.

MEM (Ministerio de Energía y Minas) (2012). Anuario Estadístico de Hidrocarburos 2011. Perú: MEM.

MEM (Ministerio de Energía y Minas) (2014). Plan energético nacional 2014-2025: Documento de trabajo. Lima, Perú: MEM, 140p. 
MEM (Ministerio de Energía y Minas) (2015). Balance nacional de energía 2014. Perú: MEM.

MEM (Ministerio de Energía y Minas) (2017). Balance nacional de energía 2016. Perú: MEM.

MEM (Ministerio de Energía y Minas) (2018a). Balance nacional de energía 2017. Perú: MEM.

MEM (Ministerio de Energía y Minas) (2018b). Anuario estadístico 2017, Sector Hidrocarburos. Perú: MEM.

MEM (Ministerio de Energía y Minas) (2019). Estadísticas [Archivos de datos]. Perú: MEM.

MEM (Ministerio de Energía y Minas) (2020). Libro Anual de Reservas de Hidrocarburos. Perú: MEM.

Minag (Ministerio de Agricultura y Riego) (2018). 2018: Anuario estadístico de producción agrícola. Perú: Minag.

Minag (Ministerio de Agricultura y Riego) (s.f.). Resumen Maple Etanol en Piura. Perú: Minag.

Minam (Ministerio del Ambiente) (2013). Actualización de Índices de Nocividad de Combustibles - INC. Perú: Minam.

ONU (Organización de las Naciones Unidas) (2007). Sustainable bioenergy: A framework for decision makers. Nueva York, Estados Unidos de América: ONU, 60p.

Osinergmin (Organismo Supervisor de la Inversión en Energía y Minería) (2012-2018). SCOP-DOCS [Archivos de datos]. Perú: Osinergmin.

PEP (Poder Ejecutivo del Perú) (2005). Decreto Supremo n. 0 013-2005-EM. Aprueba el reglamento de la Ley n.2 28054, 6p.

PEP (Poder Ejecutivo del Perú) (2007). Decreto Supremo n. ${ }^{\circ}$ 021-2007-EM. Aprueba el reglamento para la comercialización de biocombustibles, $13 \mathrm{p}$.

PEP (Poder Ejecutivo del Perú) (2008). Decreto Supremo n. 064-2008-EM. Modifica el reglamento para la comercialización de biocombustibles, $5 \mathrm{p}$.

PEP (Poder Ejecutivo del Perú) (2009a). Decreto Supremo n. ${ }^{\circ}$ 091-2009-EM. Modifica el reglamento para la comercialización de biocombustibles, 6p.

PEP (Poder Ejecutivo del Perú) (2009b). Decreto Supremo n. ㅇ 075-2009-PCM. Decreto Supremo que crea la Comisión Multisectorial sobre Bioenergía, $3 p$.

PEP (Poder Ejecutivo del Perú) (2010). Decreto Supremo n. 0 061-2010-EM. Modifica el reglamento para la comercialización de biocombustibles, $2 \mathrm{p}$.

PEP (Poder Ejecutivo del Perú) (2011). Decreto Supremo n. ${ }^{\circ}$ 024-2011-EM. Modifica el reglamento para la comercialización de biocombustibles, $1 \mathrm{p}$.

PEP (Poder Ejecutivo del Perú) (2014). Decreto Supremo n. 316-2014-EF. Modifican el Impuesto Selectivo al Consumo aplicable a los bienes contenidos en el nuevo apéndice III del Texto Único Ordenado de la Ley del Impuesto General a las Ventas e Impuesto Selectivo al Consumo, 2p. 